Review

\title{
The combination of heterogeneous photocatalysis with chemical and physical operations: A tool for improving the photoprocess performance
}

\author{
Vincenzo Augugliaro $^{a}$, Marta Litter ${ }^{\mathrm{b}, \mathrm{c}}$, Leonardo Palmisano ${ }^{\mathrm{a}, *}$ Javier Soria $^{\mathrm{d}}$ \\ a Dipartimento di Ingegneria Chimica dei Processi e dei Materiali, Università di Palermo, Viale delle Scienze, 90128 Palermo, Italy \\ ${ }^{\mathrm{b}}$ Unidad de Actividad Química, Centro Atómico Constituyentes, Comisión Nacional de Energía Atómica, Av. Gral. Paz 1499, \\ 1650 San Martín, Prov. de Buenos Aires, Argentina \\ c Escuela de Posgrado, Universidad de Gral. San Martín, Peatonal Belgrano 3563, 1650 San Martín, Prov. de Buenos Aires, Argentina \\ ${ }^{\mathrm{d}}$ Instituto de Catálisis y Petroleoquímica, CSIC, C/Marie Curie 2, Campus de Cantoblanco, 28049 Madrid, Spain
}

Received 21 June 2006; received in revised form 22 November 2006; accepted 15 December 2006

Available online 4 January 2007

\begin{abstract}
Heterogeneous photocatalysis is a process of great potential for pollutant abatement and waste treatment. In order to improve the overall performance of the photoprocess, heterogeneous photocatalysis is being combined with physical or chemical operations, which affect the chemical kinetics and/or the overall efficiency. This review addresses the various possibilities to couple heterogeneous photocatalysis with other technologies to photodegrade organic and inorganic pollutants dissolved in actual or synthetic aqueous effluents. These combinations increase the photoprocess efficiency by decreasing the reaction time in respect to the separated operations or they decrease the cost in respect of heterogeneous photocatalysis alone, generally in terms of light energy. Depending on the operation coupled with heterogeneous photocatalysis, two categories of combinations exist. When the coupling is with ultrasonic irradiation, photo-Fenton reaction, ozonation, or electrochemical treatment, the combination affects the photocatalytic mechanisms thus improving the efficiency of the photocatalytic process. When the coupling is with biological treatment, membrane reactor, membrane photoreactor, or physical adsorption, the combination does not affect the photocatalytic mechanisms but it improves the efficiency of the overall process. The choice of the coupling is related to the type of wastewater to be treated. A synergistic effect, giving rise to an improvement of the efficiency of the photocatalytic process, has been reported in the literature for many cases.
\end{abstract}

(c) 2007 Elsevier B.V. All rights reserved.

Keywords: Advanced oxidation processes; Heterogeneous photocatalysis; Sonophotocatalysis; Photocatalytic ozonation; Photocatalytic Fenton reaction; Membrane photoreactor

\section{Contents}

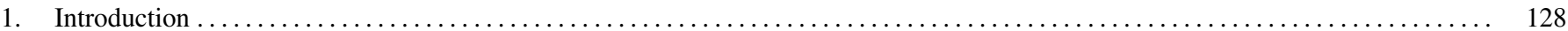

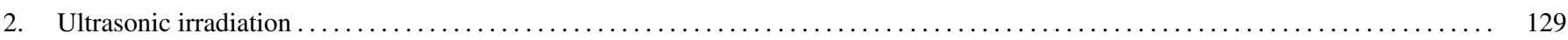

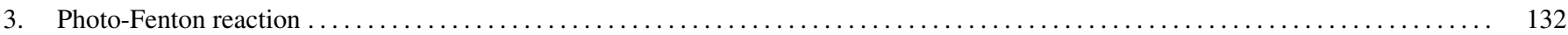

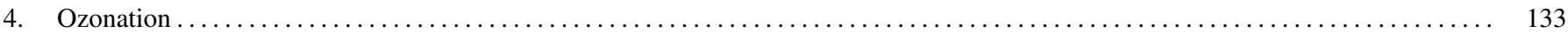

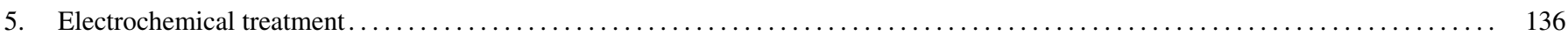

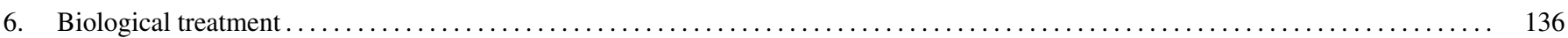

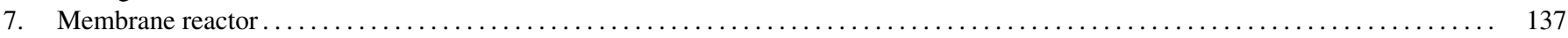

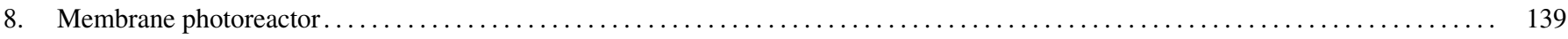

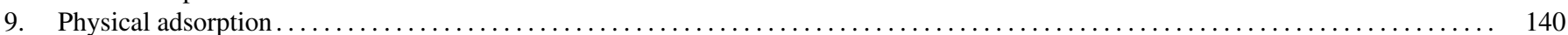

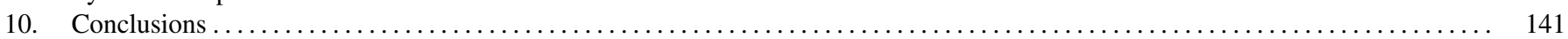

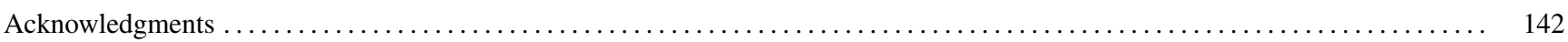

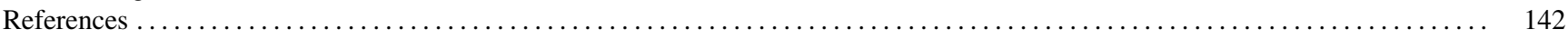

* Corresponding author. Tel.: +39091 6567246; fax: +390916567280.

E-mail addresses: augugliaro@ dicpm.unipa.it (V. Augugliaro), litter@cnea.gov.ar (M. Litter), palmisano@dicpm.unipa.it (L. Palmisano), jsoria@icp.csic.es (J. Soria). 


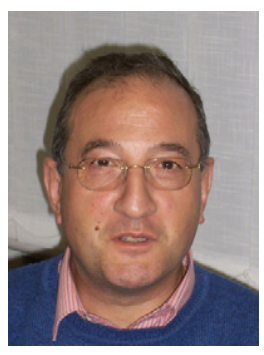

Vincenzo Augugliaro, born on 1949, received the doctor degree in chemical engineering from the University of Palermo (Italy) in 1975 cum laude. From 1978 to 1994 he has been associate professor of chemical reactor theory; from 1994 he is full professor of transport phenomena at the Faculty of Engineering of the University of Palermo. In the course of his scientific activity, prof. Vincenzo Augugliaro has contributed to the following fields: chemical absorption kinetics, biochemical reactor modelling, diffusional kinetics in metalliding alloys, chemical kinetics of heterogeneous photocatalytic systems; modelling of heterogeneous photoreactors, radiation field modelling in absorbing-reacting media, advanced oxidation processes for environment remediation.

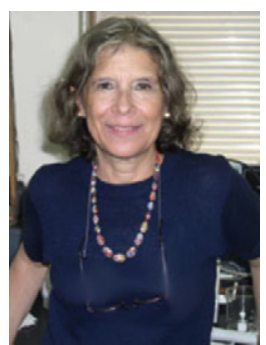

Marta Litter is doctor in chemistry from the University of Buenos Aires (UBA), Argentina, with postdoctoral formation at the Arizona University, USA. She is author of around 60 scientific publications in international journals of high impact in organic and physical chemistry and environmental sciences. She is also author of various reviews on photocatalysis and advanced oxidation processes and has contributed to the elaboration of educative documents on the subject for Spanishspeaking specialists and students. She is the Head of the Colloid and Inorganic Oxides Group, at the Chemistry Department of the National Atomic Commission of Argentina. She is also full professor at the San Martín University (Postdegree School) and member of the National Research Council (CONICET). She has been professor at UBA and at the National Technological University (Argentina) as well as at other Latin American Universities. At present, she teaches a course on water chemistry and hydric contamination for the Master in Environmental Sciences at UBA. She has directed and directs several degree, master and $\mathrm{PhD}$ thesis. She coordinates various projects on water treatment by advanced oxidation processes, especially heterogeneous photocatalysis. She is the international coordinator of the Organization of the American States OEA/AE/141 Project (low-cost technologies for disinfection and decontamination of water in rural regions of Latin America, 2002-2006), the international coordinator of the Iberoarsen Project (Arsenic in Iberoamerica), financed by CYTED (2006-2009), and a partner of the SOLWATER project (European Union, 2002-2005).

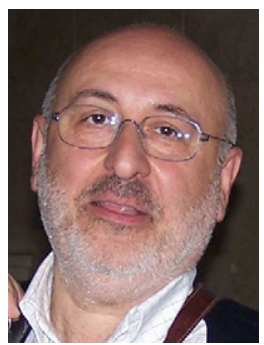

Leonardo Palmisano born on 1950, received the doctor degree in Chemistry from the University of Palermo (Italy) in 1973 cum laude. From 2000, he is full professor of chemistry at University of Palermo, Faculty of Engineering. His main field of interest is heterogeneous photocatalysis and he is author of many papers published in international journals and books and oral or poster communications in National and International Conferences. In particular, most of his work has been focussed on photodegradation of noxious organic and inorganic species by using various types of photocatalysts. He has been invited as visiting researcher (Bradford University, Bradford, UK) or visiting professor (Hokkaido University, Sapporo, Japan) or as lecturer in many universities all over the world. Moreover, he is co-author of a didactic book Fondamenti di Chimica published in Italy by Edises, and in Spain by Ariel Ciencia.

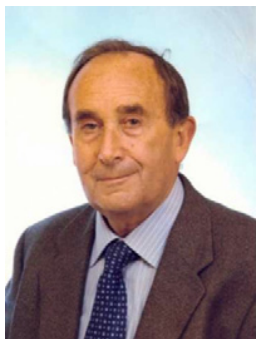

Javier Soria obtained a doctor in physics degree by the Universidad Complutense of Madrid (Spain) in 1966 and a PhD by the University of Cambridge (UK) in 1968. He continued his postdoctoral formation as research associate in the University of Princeton (USA) during 1969 and 1970. In 1966, he obtained a staff position in the Consejo Superior de Investigaciones Científicas (CSIC) of Spain. In 1988, he obtained the CSIC position of professor of research. During the period 1989-2002, he was Director of the Institute of
Catalysis and Petroleum-Chemistry of the CSIC. Most of his research work has been devoted to the study of the catalysts properties using spectroscopic techniques, mainly electron paramagnetic resonance (EPR) and infrared (FTIR) The most recurrent field of his research efforts is heterogeneous photocatalysis.

\section{Introduction}

The increasing contamination of wastewater streams by organic species refractory to conventional methods has promoted the development of newer technologies able to degrade these contaminants. Advanced oxidation processes (AOPs) are efficient novel methods useful to accelerate the non-selective oxidation and thus the destruction of a wide range of organic substances resistant to conventional technologies [1-3]. AOPs are based on physicochemical processes that produce in situ powerful transitory species, principally hydroxyl radicals $\left(\mathrm{HO}^{\bullet}\right)$, by using chemical and/or other forms of energy, and have a high efficiency for organic matter oxidation; in fact, under proper conditions the species to be removed are converted completely to $\mathrm{CO}_{2}, \mathrm{H}_{2} \mathrm{O}$ and innocuous mineral salts. There are already promising results for real applications in the near future, because very good results have been obtained in pilot plants and in larger scale in industrialized countries.

Among AOPs, heterogeneous photocatalysis using semiconductor oxides has demonstrated to be very effective to treat pollutants both in gas and in liquid phase [4-6]. The basic principles of this method are well established [7] and are briefly summarized in the following simplified process. The photoexcitation of semiconductor particles promotes an electron from the valence band to the conduction band thus leaving an electron deficiency or hole in the valence band; in this way, electron/hole pairs are generated. Both reductive and oxidative processes can occur at/or near the surface of the photoexcited semiconductor particle. In aerated aqueous suspensions, oxygen is able to scavenge conduction band electrons forming superoxide ions $\left(\mathrm{O}_{2}{ }^{\bullet-}\right)$ and its protonated form, the hydroperoxyl radical $\left(\mathrm{HO}_{2}{ }^{\bullet}\right)$ :

$\mathrm{O}_{2}+\mathrm{e}^{-} \rightarrow \mathrm{O}_{2}^{\bullet-}$

$\mathrm{O}_{2}{ }^{\bullet-}+\mathrm{H}^{+} \rightarrow \mathrm{HO}_{2}{ }^{\bullet}$

In this way, electron/hole recombination can be effectively prevented and lifetime of holes is prolonged. $\mathrm{HO}_{2}{ }^{\bullet}$ can lead to the formation of $\mathrm{H}_{2} \mathrm{O}_{2}$ :

$$
\begin{aligned}
& \mathrm{HO}_{2}{ }^{-}+\mathrm{e}^{-} \rightarrow \mathrm{HO}_{2}{ }^{-} \\
& \mathrm{HO}_{2}{ }^{-}+\mathrm{H}^{+} \rightarrow \mathrm{H}_{2} \mathrm{O}_{2}
\end{aligned}
$$

Photogenerated holes can react with adsorbed water molecules (or hydroxide anions) to give hydroxyl radicals:

$\mathrm{H}_{2} \mathrm{O}+\mathrm{h}^{+} \rightarrow \mathrm{HO}^{\bullet}+\mathrm{H}^{+}$

or they can also be filled by an adsorbed organic donor. Controversy still exists in the literature about the oxidative species; even if the photogenerated hole has the potential to oxidize several substrates by electron transfer, in aqueous solutions oxidation of water to hydroxyl radical seems to be the predominant pathway. Superoxide anion can also act as an oxidant. The whole process can end in the complete mineralization of organic compounds. 
In order to improve the overall performance of the photoprocess, heterogeneous photocatalysis has been in last times combined with physical or chemical operations, which affect the chemical kinetics and/or the overall efficiency. This review addresses only to novel combinations of heterogeneous photocatalysis with other operations. It will be seen that the combination can: (i) increase the efficiency and decrease the reaction time in respect to the separated operations; (ii) decrease the cost in respect of heterogeneous photocatalysis alone, generally in terms of light energy. The combinations of heterogeneous photocatalysis may be divided in two main categories:

- heterogeneous photocatalysis is coupled with an operation that affects the photocatalytic mechanisms thus improving the efficiency of the photocatalytic process. In this case, the coupling is with:

- ultrasonic irradiation;

- photo-Fenton reaction;

- ozonation;

- electrochemical treatment.

- heterogeneous photocatalysis is coupled with an operation that does not affect the photocatalytic mechanisms but improves the efficiency of the overall process. In this case the coupling is with:

- biological treatment;

- membrane reactor;

- membrane photoreactor;

- physical adsorption.

\section{Ultrasonic irradiation}

Sonochemical treatment of waters and wastewaters is based on the use of ultrasound at low to medium frequency $(20-1000 \mathrm{kHz})$ and high-energy to catalyze the destruction of organic pollutants. Typically, these treatments operate at ambient conditions and do not require the addition of extra chemicals. The chemical effects of ultrasound in aqueous solution are due to the propagation of a pressure wave, which leads to the occurrence of cavitation phenomenon, i.e., nucleation, growth and collapse of bubbles in the liquid. The collapse of the bubbles induces localized supercritical conditions: high temperature and pressure (more than $5000 \mathrm{~K}$ and $1000 \mathrm{~atm}$ [8]), electrical discharge and plasma effects. The consequences of these extreme conditions are the cleavage of dioxygen and water molecules [9] to produce active species, such as $\mathrm{H}^{\bullet}$ and $\mathrm{HO}^{\bullet}$ radicals:

$\mathrm{H}_{2} \mathrm{O} \rightarrow \mathrm{H}^{\bullet}+\mathrm{HO}^{\bullet}$

capable of attacking the organic compounds in water. Hydrogen radicals from the above reaction can also interact with the oxygen present in the system to form peroxide radicals, $\mathrm{HO}_{2}{ }^{\circ}$, and hydrogen peroxide, $\mathrm{H}_{2} \mathrm{O}_{2}$.

Different research groups under rather different experimental conditions [10-20] have recently examined the combination of ultrasound and photocatalysis (sonophotocatalysis). The simultaneous use of both techniques for degradation of organic pollutants in water was reported to be more effective than their sequential combination [13] and in several cases to lead to more than additive effects [14]. When photocatalysis was combined with high frequency sonolysis, the overall degradation rate was found to be equal to the sum of the individual rates for photocatalysis and sonolysis $[13,15]$ and beneficial effects were noticed on the mineralization rate [16]. When photocatalysis was combined with low frequency ultrasound, strong synergistic effects [15,17-19] or no effect [20], also depending on the specific ultrasound power [12], have been reported.

It may be noted that heterogeneous photocatalysis and ultrasonic irradiation can cause degradation of organic pollutants in water by the same species, notably $\mathrm{HO}^{\bullet}$ radicals [21]. However, distinct phenomena can also be involved; photocatalytic reactions may occur through direct electron transfer from the organic compounds to the semiconductor oxide and ultrasonic irradiation may selectively degrade less hydrophilic compounds through thermal degradation reactions (pyrolysis). The observed synergistic effect $[20,22]$ may be justified by different reasons. In fact, for the ultrasonic treatment the presence of solid particles in the aqueous system enhances the cavitation phenomenon $[23,24]$ as the microbubbles tend to break up into smaller ones thus increasing the total number of regions of high temperature and pressure. As a consequence, the number of hydroxyl radicals produced by the system increases thus improving the oxidation capacity of the system. For the photocatalytic process, the acceleration of reactions is determined not only by chemical effects of ultrasound irradiation but also by mechanical effects caused by the ultrasonic waves, such as particle size reduction, increased mass transfer and surface cleaning, which hinder the blocking of the catalyst active sites by reaction intermediates.

Guillard et al. [25] studied octanol degradation by separately applying photocatalytic and ultrasound process in order to elucidate the reaction mechanisms. They used the solid phase microextraction technique for identifying, quantifying and following the evolution of intermediate products deriving from the degradation. For both processes, $\mathrm{HO}^{\bullet}$ radicals induce the formation of various aldehydes (as main intermediates) by $\mathrm{H}$ abstraction and reaction with oxygen. However, their amount and their evolution differ when comparing both processes. The amount of octanal produced by ultrasound is not as important as that produced by photocatalysis. Smaller aldehydes are formed by ultrasound from the beginning of the degradation process. The authors [25] conclude that, in spite of the formation of the same main active species, the specificity of each process, i.e., high pressure and temperature in cavitation bubbles in ultrasound and the presence of electron-hole pairs in photocatalysis, leads to the formation of different intermediate products and, consequently, different pathways take place.

Stock et al. [13], by studying the degradation of an azo-dye (Naphtol Blue) under high frequency ultrasound and UV photolysis, found that sonolysis is effective for inducing a higher degradation rate while photolysis is effective for promoting mineralization.

The sonophotocatalytic degradation of salicylic acid on commercial $\mathrm{TiO}_{2}$ catalysts was studied by Davydov et al. [20]. Experiments with titania, UV light, ultrasound, combination of UV light and titania, and UV light with titania and ultrasound 
were performed separately to determine which factor had the major influence on the degradation of salicylic acid. The rate of photodegradation of salicylic acid was previously found [26] to obey zero order kinetics at relatively low conversion and first order kinetics at higher conversion. For Davydov et al. [20], the order of the reaction was always zero. As mass transfer limitations cannot justify this discrepancy, the absence of the shifting order in the degradation kinetics was attributed to two effects associated with the interaction of ultrasound and solid matter: micro-streaming and increased mass transport. Micro-streaming provides in situ regeneration of catalyst surface as the cavitation bubbles near the solid surface cause a jet of fluid directed onto the particle [27]. In this manner, the partial blockage of the active sites of the photocatalyst (leading to the reduction of adsorption capacity) can be circumvented. Ultrasound can also enhance the mass transfer towards the liquid-solid interface [28]. This supplies more salicylic acid molecules to the catalyst surface and effectively enhances the adsorption of reactant bringing it closer to saturation, which may be otherwise impaired due to the larger size of the salicylic acid molecule.

Theron et al. [15] studied the degradation of formic acid by sonophotocatalysis; they propose the deaggregation of the catalyst and the photocatalytic utilization of $\mathrm{H}_{2} \mathrm{O}_{2}$ produced by the ultrasound as the main reasons of the synergistic effect of ultrasound and photocatalysis.

Semiconductor-loaded zeolites and mesoporous molecular sieves have recently drawn increased attention $[29,30]$ as potential photocatalysts due to their unique pore structure. The advantages of using zeolite or molecular sieves as supports for $\mathrm{TiO}_{2}$ are: (i) formation of ultrafine $\mathrm{TiO}_{2}$ particles during sol-gel deposition; (ii) increased adsorption properties, especially for non-polar compounds; (iii) higher acidity which allows to enhance electron abstraction; and (iv) less UV light scattering as silica is the main component of zeolite.

Reddy et al. [31] investigated different $\mathrm{TiO}_{2}$-loaded zeolites and mesoporous materials for the sonophotocatalytic destruction of salicylic acid in aqueous solution. Their system combines the advantages of all three ways of pollution abatement: photocatalysis, sonolysis and use of zeolite materials. Ultrasound resistant zeolitic and mesoporous supports were isolated, loaded with $\mathrm{TiO}_{2}$, characterized and then used for the degradation of salicylic acid. The experimental results indicate that the degradation of salicylic acid by photocatalysis was less effective than that by sonophotocatalysis, clearly showing that the effect of ultrasound was the basis of the increase of the efficiency. It was also found that the higher rate was observed on $\mathrm{TiO}_{2}$-loaded mesoporous molecular sieve due to the more hydrophilic nature of that titania.

Shirgaonkar and Pandit [14] studied the photodegradation of 2,4,6-trichlorophenol in irradiated $\mathrm{TiO}_{2}$ slurries with ultrasound and found enhancement of the quantum yield.

$\mathrm{TiO}_{2}$ photocatalytic degradation is not satisfactory for the treatment of dye-containing wastewaters; in fact, the penetration ability of light in non-transparent dye-containing wastewaters are limited (penetration depth is only several millimetres). If ultraviolet as well as visible light are used together with $\mathrm{TiO}_{2}$ based catalysts, the efficiency of utilization of light is quite low. These disadvantages can be overcome by using ultrasound, because of the strong penetrating ability of this type of irradiation in any water medium, whose penetration depth can ordinarily attain $15-20 \mathrm{~cm}$ [32].

Mrowetz et al. [18] investigated the degradation of 2chlorophenol and of two azo-dyes (Orange 8 and Acid Red 1) in aqueous $\mathrm{TiO}_{2}$ suspensions under sonophotocatalysis. The investigated pollutants underwent relatively slow degradation under ultrasound in the presence of titanium dioxide (no light), while under photocatalysis the degradation occurred at a higher rate. The cleavage of the azo double bond was identified as one of the first degradation steps in both photocatalytic and sonolytic degradation. A significant increase in the reaction rate was observed when the illuminated $\mathrm{TiO}_{2}$-suspensions were simultaneously sonicated. More interestingly, a synergistic effect was evidenced: the combined effect of sonolysis and photocatalysis led to a degradation rate greater than the sum of the degradation rate constants measured under photocatalysis and sonolysis. The enhancement in the degradation rate under sonophotocatalytic conditions was related to an increase in the cavitational activity in the presence of an additional phase [12,14], although effects due to the capability of $\mathrm{TiO}_{2}$ to absorb the light produced by sonoluminescence were not excluded. The authors propose to quantify the synergy between photocatalysis and sonolysis by a parameter calculated as the difference between the sonophotocatalytic rate constant and the sum of those obtained under separate photocatalysis and sonolysis in the presence of semiconductor; this difference is normalized with respect to the sonophotocatalytic rate constant.

The role played by $\mathrm{H}_{2} \mathrm{O}_{2}$ in sonophotocatalytic processes has been the object of extensive investigations. Mrowetz et al. [18] performed a systematic study in order to understand the origin of the observed synergistic effect and to ascertain whether it is a consequence of processes occurring at the water-semiconductor interface or in the aqueous phase. Sonolysis might increase the photocatalytic activity in a non-specific way: this could occur through the size decrease of particles consequent to ultrasound deaggregation leading to an increase in surface area and thus of catalytic performance. However, when photocatalytic runs were carried out employing presonicated $\mathrm{TiO}_{2}$, both substrate degradation and mineralization proceeded at an only slightly higher rate than that found in the presence of untreated $\mathrm{TiO}_{2}$. This finding is in line with the fact that the sequential application of sonolysis and photocatalysis led to less than additive reaction rates. On the basis of the degradation rate results, the authors suggest that the synergy should not be attributed to water-semiconductor interface phenomena but should rather involve active species in the aqueous phase. Hydrogen peroxide is known to be produced by both photocatalysis and sonolysis in water: under photocatalysis $\mathrm{H}_{2} \mathrm{O}_{2}$ is formed mainly by the reduction of adsorbed dioxygen by conduction band electrons [33], while sonolysis of water produces $\mathrm{H}_{2} \mathrm{O}_{2}$ as a result of recombination between hydroxyl radicals produced by the implosion of cavitation bubbles [34]. By monitoring $\mathrm{H}_{2} \mathrm{O}_{2}$ formation during the degradation runs, the authors [18] conclude that the sonophotocatalytic synergistic effect is strictly related to the accumulation of hydrogen peroxide in the aqueous phase. 
No synergy is observed when $\mathrm{H}_{2} \mathrm{O}_{2}$ does not accumulate in the system.

The effect of hydrogen peroxide addition on the kinetics of methyl-tert-butyl ether (MTBE) degradation in water by sonophotocatalysis was investigated by Bertelli and Selli [35]. The combined use of photocatalysis and sonolysis in the absence of $\mathrm{H}_{2} \mathrm{O}_{2}$ led to a MTBE degradation rate about equal to the sum of those measured under only sonolysis or photocatalysis. This additive effect may be justified by the fact that the ultrasoundinduced degradation of MTBE, a rather volatile substrate, mainly occurs in the vapour phase of the cavitation bubbles and not in the bulk aqueous phase. With less volatile substrates [17], a strong synergistic effect between sonolysis and photocatalysis was observed and attributed to effects able to enhance the rate of substrate degradation in the aqueous phase, i.e. to increased mass transfer [19] and to the ultrasound-increased scission of the photocatalytically produced $\mathrm{H}_{2} \mathrm{O}_{2}$ [17]. In the presence of added $\mathrm{H}_{2} \mathrm{O}_{2}, \mathrm{HO}^{\bullet}$ radicals are produced both by the ultrasoundinduced scission and by the UV-induced photolysis of hydrogen peroxide in the aqueous phase. Under photocatalytic conditions, instead, $\mathrm{HO}^{\bullet}$ radicals are mainly produced through the interface oxidation of hydroxide anions or water molecules adsorbed on the semiconductor surface by the holes photoproduced in the semiconductor valence band. The synergistic effect may be attributed to the fact that ultrasound contributes in maintaining $\mathrm{H}_{2} \mathrm{O}_{2}$ in the aqueous phase by inhibiting its adsorption and subsequent photodegradation on the $\mathrm{TiO}_{2}$ surface.

Selli et al. [36] also performed a comparison between the kinetic results of MTBE degradation in water in an $\mathrm{O}_{2} / \mathrm{Ar}$ atmosphere employing low frequency sonolysis (at $20 \mathrm{kHz}$ ) and photocatalysis in the presence of $\mathrm{TiO}_{2}$, either separately or in combination. The scheme of the experimental set-up employed for the degradation runs is reported in Fig. 1. The rate constant of MTBE degradation under sonophotocatalytic conditions was slightly greater than the sum of those obtained under sonolysis and photocatalysis alone. A higher degradation rate was observed when ultrasound was applied in the absence of stirring while no difference was observed for less volatile substrates. This confirms the hypothesis that the ultrasound-induced degradation of MTBE mainly occurs through direct pyrolysis in the vapour phase of the cavitation bubbles within the hot interfacial region between the vapour and the surrounding liquid phases $[37,38]$, instead of being mediated by the ultrasound produced $\mathrm{HO}^{\bullet}$ radicals in the aqueous phase, as in the case of less volatile substrates. Indeed, compounds with a high vapour pressure can enter the cavitation bubbles, where they undergo thermolytic reactions, while hydrophilic compounds undergo preferential hydroxylation reactions out of the bubble either in the limit layer or in the bulk solution.

The complete mineralization of propyzamide, a common and dangerous herbicide, in $\mathrm{TiO}_{2}$-aqueous suspension by sonophotocatalysis was performed by Yano et al. [39]. No TOC change was evident under ultrasonic irradiation alone, while the simultaneous irradiation with light and ultrasonic waves was able to slowly mineralize propyzamide. Moreover, complete mineralization was quickly achieved by sonophotocatalysis in the presence of $\mathrm{H}_{2} \mathrm{O}_{2}$.

Velegraki et al. [40] carried out the oxidation of Acid Orange 7 by sonophotocatalysis and investigated the effect of reaction temperature, ultrasound frequency and periodicity of irradiation on conversion. Under similar treatment conditions, ultrasound irradiation resulted in higher conversion than photocatalysis. Moreover, different reaction pathways were observed: the sonochemically irradiated solution consistently contained low aliphatic intermediates, while the photocatalytically treated solution mainly consisted of aromatic intermediates.

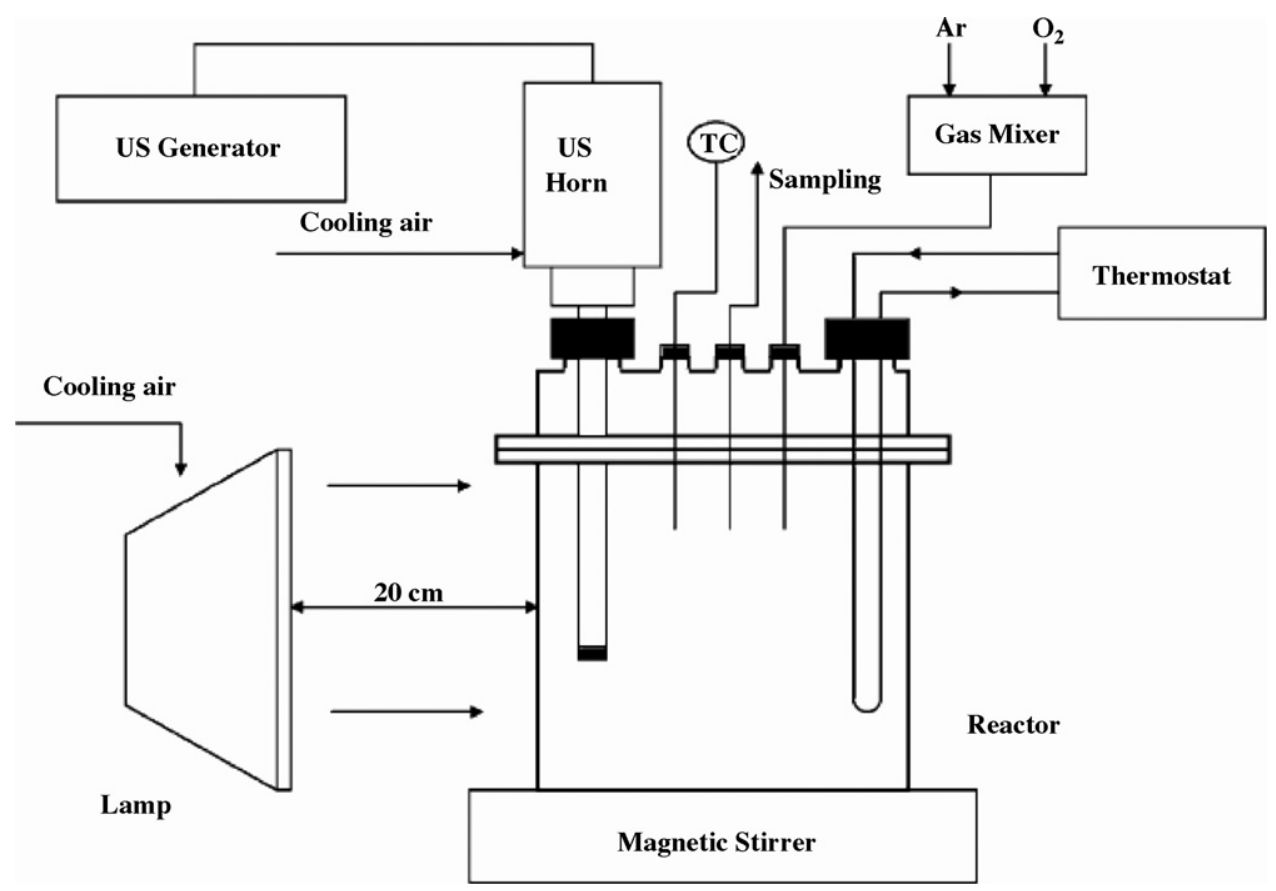

Fig. 1. Scheme of the experimental set-up employed for methyl-tert-butyl ether degradation in water by sonophotocatalysis [36]. 
Sonophotocatalysis has been used also for performing reactions different from oxidative degradation. The water splitting in liquid phase was demonstrated using the sonophotocatalytic technique in the presence of $\mathrm{TiO}_{2}$ under white light illumination from a Xe lamp [41]. In the case of sonophotocatalysis, it is proposed that overall water splitting proceeds by a two-step reaction, as follows:

$4 \mathrm{H}_{2} \mathrm{O} \rightarrow 2 \mathrm{H}_{2}+2 \mathrm{H}_{2} \mathrm{O}_{2} \quad$ (sonochemical process)

$2 \mathrm{H}_{2} \mathrm{O}_{2} \rightarrow \mathrm{O}_{2}+2 \mathrm{H}_{2} \mathrm{O}$ (photocatalytic process)

Harada et al. [42] studied the overall water splitting using $\mathrm{BiVO}_{4}$, a visible-light sensitive photocatalyst. By considering the above reported reactions, they examined the photocatalytic decomposition of $\mathrm{H}_{2} \mathrm{O}_{2}$ in spite of the fact that it is a downhill reaction. The simultaneous irradiation with visible light and ultrasound yielded the continuous and stoichiometric liquid water decomposition to $\mathrm{H}_{2}$ and $\mathrm{O}_{2}$.

In order to achieve photosynthesis-like reactions, Harada et al. [43] carried out the sonophotocatalysis of water in a 3.5\% $\mathrm{CO}_{2}-\mathrm{Ar}$ atmosphere, resulting in reduction of $\mathrm{CO}_{2}$ to $\mathrm{CO}$ and continuous generation of $\mathrm{O}_{2}$ from water. The reactions are formally shown below:

$$
\begin{aligned}
& 4 \mathrm{H}_{2} \mathrm{O} \rightarrow 2 \mathrm{H}_{2}+2 \mathrm{H}_{2} \mathrm{O}_{2} \quad \text { (sonochemical process) } \\
& 2 \mathrm{H}_{2} \mathrm{O}_{2} \rightarrow \mathrm{O}_{2}+2 \mathrm{H}_{2} \mathrm{O} \quad \text { (photocatalytic process) } \\
& 2 \mathrm{CO}_{2}+2 \mathrm{H}_{2} \rightarrow 2 \mathrm{CO}+2 \mathrm{H}_{2} \mathrm{O} \quad\left(\mathrm{CO}_{2}\right. \text { sonolysis) } \\
& 2 \mathrm{CO}_{2} \rightarrow 2 \mathrm{CO}+\mathrm{O}_{2} \quad \text { (total reaction) }
\end{aligned}
$$

Although photocatalysis alone could not split water into $\mathrm{H}_{2}$ and $\mathrm{O}_{2}$, a combined system of photocatalysis and sonolysis could drive water splitting. Similarly, $\mathrm{CO}_{2}$ is negligibly reduced by photocatalysis, while it was reduced by sonolysis. By a combination of photocatalysis and sonolysis, the overall $\mathrm{CO}_{2}$ deoxygenation into $\mathrm{CO}$ and $\mathrm{O}_{2}$ could be performed.

\section{Photo-Fenton reaction}

The Fenton reaction is a dark process whose application for destroying toxic organic compounds began in 1960 [44]. In the absence of light, the most accepted mechanism of $\mathrm{H}_{2} \mathrm{O}_{2}$ decomposition by $\mathrm{Fe}^{2+}$ ions involves the production of $\mathrm{HO}^{\bullet}$ radicals [45]:

$\mathrm{Fe}_{\mathrm{aq}}^{2+}+\mathrm{H}_{2} \mathrm{O}_{2} \rightarrow \mathrm{Fe}_{\mathrm{aq}}^{3+}+\mathrm{OH}^{-}+\mathrm{HO}^{\bullet}$

The $\mathrm{Fe}^{2+}$ regeneration follows different paths as:

$$
\begin{aligned}
& \mathrm{Fe}_{\mathrm{aq}}^{3+}+\mathrm{H}_{2} \mathrm{O}_{2} \rightarrow \mathrm{Fe}_{\mathrm{aq}}^{2+}+\mathrm{HO}_{2}^{\bullet}+\mathrm{H}^{+} \\
& \mathrm{Fe}_{\mathrm{aq}}^{3+}+\mathrm{HO}_{2}^{\bullet} \rightarrow \mathrm{Fe}_{\mathrm{aq}}^{2+}+\mathrm{O}_{2}+\mathrm{H}^{+}
\end{aligned}
$$

In the presence of UV-vis light, Fenton reaction rates are strongly increased. The positive effect of light on the degradation rate is due to the iron recycling caused by the photochemical reduction of ferric ions that concomitantly lead to additional $\mathrm{HO}^{\bullet}$ radical generation:

$\mathrm{Fe}(\mathrm{OH})^{2+}+h v \rightarrow \mathrm{Fe}^{2+}+\mathrm{HO}^{\bullet}$

The new generated $\mathrm{Fe}^{2+}$ ion reacts with $\mathrm{H}_{2} \mathrm{O}_{2}$ giving $\mathrm{HO}^{\bullet}$ radical and $\mathrm{Fe}^{3+}$ ion, and the cycle continues; in these conditions, iron behaves as a real catalyst. This type of homogeneous photoassisted reaction is referred to the photo-Fenton reaction; its main advantage is that the reaction occurs at radiation wavelengths up to $600 \mathrm{~nm}$ so that it may utilize a great part of the solar irradiation.

It is known [7,46,47] that addition of $\mathrm{H}_{2} \mathrm{O}_{2}$ enhances photocatalytic reactions due to inhibition of electron-hole recombination and production of additional $\mathrm{HO}^{\bullet}$ radicals through reaction with conduction band electrons or with superoxide radicals, especially at high $\mathrm{H}_{2} \mathrm{O}_{2}$ concentrations:

$$
\begin{aligned}
& \mathrm{H}_{2} \mathrm{O}_{2}+\mathrm{e}^{-} \rightarrow \mathrm{HO}^{\bullet}+\mathrm{HO}^{-} \\
& \mathrm{O}_{2}^{\bullet-}+\mathrm{H}_{2} \mathrm{O}_{2} \rightarrow \mathrm{O}_{2}+\mathrm{HO}^{\bullet}+\mathrm{HO}^{-}
\end{aligned}
$$

However, an excess of $\mathrm{H}_{2} \mathrm{O}_{2}$ can be detrimental because it is a hole scavenger and the produced hydroperoxyl radical has a less oxidizing power than $\mathrm{HO}^{\bullet}$ :

$\mathrm{HO}^{\bullet}+\mathrm{H}_{2} \mathrm{O}_{2} \rightarrow \mathrm{HO}_{2}^{\bullet}+\mathrm{H}_{2} \mathrm{O}$

The combination of $\mathrm{Fe}(\mathrm{III}), \mathrm{H}_{2} \mathrm{O}_{2}, \mathrm{TiO}_{2}$ and irradiation, i.e., photo-Fenton and photocatalysis, improves the destruction of some resistant pollutants. It has been reported that ethylenediaminetetraacetic acid (EDTA), nitrilotriacetic acid (NTA) and other oligocarboxylic acids are more rapidly mineralized in the presence of $\mathrm{Fe}(\mathrm{III}) / \mathrm{H}_{2} \mathrm{O}_{2}$ than when using $\mathrm{TiO}_{2}$ alone [48-53]. Heterogeneous photocatalysis and photo-Fenton reaction were combined and the resulting process notably accelerated the degradation of the organic acids. In the case of EDTA, although photocatalytic degradation is rather fast, mineralization is difficult due to the formation of resistant intermediates; addition of oxidants like $\mathrm{Fe}$ (III) or $\mathrm{H}_{2} \mathrm{O}_{2}$ improves TOC removal. Oxalic acid does not give rise to intermediates alongside its degradation, TOC reduction paralleling the decrease of oxalic acid concentration. One important difference between EDTA and oxalic acid comes from the different quantum yields of the photolysis of the respective $\mathrm{Fe}(\mathrm{III})$-complexes, more than one order of magnitude lower for Fe-EDTA. Therefore, for EDTA the degradation promoted by heterogeneous photocatalysis is important, the homogeneous process contributing only to a lesser extent. In contrast, in the oxalic acid system, $\mathrm{TiO}_{2}$ would act as a screen or optical filter, reducing the efficiency of $\mathrm{H}_{2} \mathrm{O}_{2}$ photolysis.

In related reactions, the presence of $\mathrm{Fe}$ (III)-complexes, such as Fe(III)-NTA helps photocatalytic degradation of 4chlorophenol [54,55]. In these cases, an important effect of the $\mathrm{Fe}$ (III)-complexes formed with the initial compound or with possible degradation intermediates takes place: these complexes can be photolyzed and even photocatalyzed in the reaction medium, generating $\mathrm{Fe}$ (II) and other active radical species.

Disinfection of drinking water by photocatalysis and photoFenton reaction was performed by Rincón and Pulgarin [56]. Water contaminated with Escherichia coli was treated with 
the combined method by monitoring the bacterial culturability with time. The method is suitable for performing the bacterial inactivation, the rate being higher with respect to those of photocatalysis and photo-Fenton reaction alone; however, the authors outline that the evaluation of the systems is very dependent on the relative concentrations of $\mathrm{Fe}^{3+}, \mathrm{H}_{2} \mathrm{O}_{2}$ and $\mathrm{TiO}_{2}$.

\section{Ozonation}

Despite that photocatalysis has shown to be adequate for the destruction of a wide variety of compounds, in some cases the complete mineralization is slowly attained and the efficiency of the process, in terms of energy consumption, is advantageous only for very dilute effluents $[4,5,57]$. Unlike photocatalysis, ozonation is capable of selectively destroying recalcitrant organics and it is more efficient for treating highly concentrated samples. In last times, ozonation has been increasingly used for drinking water treatment, because this method does not produce chlorinated compounds that can be originated in disinfection with chlorine or chlorine oxide. It is well known that the use of ozone allows a remarkable improvement of organoleptic properties, filtration characteristics and biodegradability of drinking water.

Ozone is a powerful oxidizing agent $\left(E^{0}=2.08 \mathrm{~V}\right)$, when compared to other agents, such as $\mathrm{H}_{2} \mathrm{O}_{2}\left(E^{0}=1.78 \mathrm{~V}\right)$, and can react with several classes of compounds through direct or indirect reactions. In the absence of light, ozone can react directly with an organic substrate, $\mathrm{S}$, through slow and selective reactions of electrophilic substitution or dipolar cycloaddition [58-61]:

$\mathrm{O}_{3}+\mathrm{S} \rightarrow \mathrm{S}_{\mathrm{ox}}$

This reaction is important in acid media and for solutes that react very fast with ozone. The electrophilic attack may occur at atoms with a negative charge density (e.g. N, P, O or nucleophilic carbons) or to double/triple bonds like carbon-carbon, carbon-nitrogen and nitrogen-nitrogen.

Ozone can also react indirectly through a fast and nonselective reaction by the $\mathrm{HO}^{\bullet}$ free radical generated by its decomposition, more favoured in alkaline media:

$2 \mathrm{O}_{3}+2 \mathrm{H}_{2} \mathrm{O} \rightarrow 2 \mathrm{HO}^{\bullet}+\mathrm{O}_{2}+2 \mathrm{HO}_{2}^{\bullet}$

The $\mathrm{HO}^{\bullet}$ radical is a powerful and non-selective oxidant that can react in aqueous solution through three possible mechanisms: (i) hydrogen abstraction; (ii) electron transfer; and (iii) radical addition. The secondary radicals formed during this reaction can react with ozone or other compounds.

The main drawback of these routes is that they lead to a very limited mineralization of the organic compounds, so it is necessary to modify the method when the complete removal of pollutant and its degradation intermediates is required. The most common way for improving the ozonation process is the addition of hydrogen peroxide and/or UV radiation.

Addition of hydrogen peroxide to the ozonation system produces a sensible improvement [62]. The process, called Perozone, combines the direct and indirect ozone oxidation of organic compounds. $\mathrm{H}_{2} \mathrm{O}_{2}$ initiates $\mathrm{O}_{3}$ decomposition by elec- tron transfer $[44,63]$ through a reaction that can be envisaged as the activation of $\mathrm{H}_{2} \mathrm{O}_{2}$ by ozone:

$\mathrm{O}_{3}+\mathrm{H}_{2} \mathrm{O}_{2} \rightarrow \mathrm{HO}^{\bullet}+\mathrm{O}_{2}+\mathrm{HO}_{2}^{\bullet}$

The process is expensive but fast, and can treat organic pollutants at very low concentrations $(\mu \mathrm{g} / \mathrm{L})$, at $\mathrm{pH}$ between 7 and 8.

Irradiation of ozone in water with near-UV light (wavelengths $>300 \mathrm{~nm}$ ) produces $\mathrm{H}_{2} \mathrm{O}_{2}$ quantitatively:

$\mathrm{O}_{3}+\mathrm{H}_{2} \mathrm{O}+h v \rightarrow \mathrm{H}_{2} \mathrm{O}_{2}+\mathrm{O}_{2}$

The generated hydrogen peroxide is photolyzed, producing $\mathrm{HO} \bullet$ radicals:

$\mathrm{H}_{2} \mathrm{O}_{2}+h v \rightarrow 2 \mathrm{HO}^{\bullet}$

This combination might be considered in principle only an expensive form of generating $\mathrm{H}_{2} \mathrm{O}_{2}$ and then $\mathrm{HO}^{\bullet}$. Indeed, it is a combination of $\mathrm{UV} / \mathrm{H}_{2} \mathrm{O}_{2}$ and $\mathrm{O}_{3} / \mathrm{H}_{2} \mathrm{O}_{2}$, but the advantage is that at $254 \mathrm{~nm}$ ozone has a higher absorption coefficient than $\mathrm{H}_{2} \mathrm{O}_{2}\left(\varepsilon_{254}=3300 \mathrm{M}^{-1} \mathrm{~cm}^{-1}\right.$ versus $\left.18.6 \mathrm{M}^{-1} \mathrm{~cm}^{-1}\right)$, and can be used to treat water with high UV absorption background. The efficiency is higher than that of $\mathrm{O}_{3}$ or direct $\mathrm{UV}$, and the reactor does not need to be in quartz because UV-B light (280-315 nm) can also be used.

If wavelengths lower than $300 \mathrm{~nm}$ are employed, photolysis of $\mathrm{O}_{3}$ takes place, generating additional $\mathrm{HO}^{\bullet}$ and other oxidants, with the subsequent increase of the efficiency [64]:

$\mathrm{O}_{3}+h v \rightarrow \mathrm{O}_{2}\left({ }^{1} \Delta \mathrm{g}\right)+\mathrm{O}\left({ }^{1} \mathrm{D}\right)$

$\mathrm{O}\left({ }^{1} \mathrm{D}\right)+\mathrm{H}_{2} \mathrm{O} \rightarrow 2 \mathrm{HO}^{\bullet}$

In conclusion, the addition of light to the $\mathrm{H}_{2} \mathrm{O}_{2} / \mathrm{O}_{3}$ process produces a net increase on the efficiency for decontamination of groundwater and for soil remediation $[65,66]$. On this basis, the simultaneous application of ozonation and photocatalysis [67-71], hereafter indicated as photocatalytic ozonation, has potential use for the efficient treatment of contaminated waters in a wide range of concentrations. When $\mathrm{O}_{3}$ is present in a photocatalytic suspension, in addition to the homogeneous pathways of direct ozonation, the role of $\mathrm{O}_{3}$ as an electron trap must be considered. FTIR studies [72,73] report different modes of ozone interaction with $\mathrm{TiO}_{2}$ surface, such as: (i) physical adsorption; (ii) formation of weak hydrogen bonds with surface hydroxyl groups of the catalyst; and (iii) dissociative adsorption on strong surface Lewis acid sites leading to $\mathrm{O}_{3}$ decomposition with formation of a free oxygen molecule and a surface oxygen atom that remains attached to the site [73].

In the presence of $\mathrm{TiO}_{2}$ and near-UV radiation, adsorbed ozone acts as a very strong electrophilic agent generating an ozonide radical, $\mathrm{O}_{3}{ }^{\bullet-}$, whose further reactions produce eventually $\mathrm{HO}^{\bullet}$ radicals in the adsorption layer [74]:

$$
\begin{aligned}
& \mathrm{O}_{3(\text { ads })}+\mathrm{e}_{\mathrm{cb}}^{-} \rightarrow \mathrm{O}_{3}^{\bullet-} \\
& \mathrm{O}_{3}^{\bullet-}+\mathrm{H}^{+} \rightarrow \mathrm{HO}_{3}^{\bullet} \\
& \mathrm{HO}_{3}^{\bullet} \rightarrow \mathrm{HO}^{\bullet}+\mathrm{O}_{2}
\end{aligned}
$$


The above reported mechanism gives rise to the formation of one hydroxyl radical per each trapped electron. In conventional photocatalytic processes, oxygen is used as the oxidant compound. The disadvantages of using oxygen as electron trap are the slow electron transfer from $\mathrm{TiO}_{2}$ to $\mathrm{O}_{2}[5]$ and the fact that three electrons are needed for the generation of a hydroxyl radical [75]:

$$
\begin{aligned}
& 3 \mathrm{O}_{2(\mathrm{ads})}+3 \mathrm{e}_{\mathrm{cb}}{ }^{-} \rightarrow 3 \mathrm{O}_{2}^{\bullet-} \\
& 2 \mathrm{O}_{2}^{\bullet-}+2 \mathrm{H}_{2} \mathrm{O} \rightarrow 2 \mathrm{HO}_{2}^{\bullet}+2 \mathrm{OH}^{-} \\
& 2 \mathrm{HO}_{2} \bullet \rightarrow \mathrm{O}_{2}+\mathrm{H}_{2} \mathrm{O}_{2} \\
& \mathrm{H}_{2} \mathrm{O}_{2}+\mathrm{O}_{2}^{\bullet-} \rightarrow \mathrm{HO}^{-}+\mathrm{HO}^{\bullet}+\mathrm{O}_{2}
\end{aligned}
$$

Consequently, when the photocatalyst is irradiated in the presence of $\mathrm{O}_{3}$, a greater number of $\mathrm{HO}^{\bullet}$ radicals is produced. Ozone therefore acts as a powerful oxidant in place of oxygen, mainly owing to the fact that $\mathrm{O}_{3}$ is more electrophilic than $\mathrm{O}_{2}$ towards electron photogenerated onto the $\mathrm{TiO}_{2}$ surface [76-78]. $\mathrm{HO}^{\bullet}$ generation from $\mathrm{O}_{3}$ is $\mathrm{pH}$ dependent and increases with decreasing $\mathrm{pH}$; this avoids the use of high alkaline $\mathrm{pH}$ to induce $\mathrm{HO}{ }^{\bullet}$ formation from $\mathrm{O}_{3}$.

The favourable effect of ozone has been tested in the photocatalytic degradation of formic, acetic and propionic acids [79] and monochloroacetic acid [80]. The combined system proved to be the most effective; the degradation was accompanied by a continuous decrease of the dissolved organic carbon content, and aldehydes and carboxylic acids containing one carbon atom less than the starting material were formed as intermediates.

Muller et al. [81] used the photocatalytic ozonation for the treatment of waters polluted by 2,4-dichlorophenoxyacetic acid (2,4-D). The advantages of photocatalysis, giving a constant decline in total organic carbon content, and of ozonation, giving no build up of high intermediate concentrations, were profited. Comparing ozonation, photocatalysis and the combination of both, they found that the combination approach reached the highest reaction rate. Nevertheless, the resulting rate was lower than a result assuming a simple addition of the rates of photocatalysis and ozonation. For this reason, the authors propose that either ozone has an inhibiting effect on photocatalysis or the high surface of the catalyst is responsible for the decay of ozone without a reaction with 2,4-D.

Sánchez et al. [82] applied the photocatalytic ozonation to the degradation of aniline in aqueous suspensions of P25 Degussa $\mathrm{TiO}_{2}$. A synergistic effect exists between $\mathrm{TiO}_{2}$ and $\mathrm{O}_{3}$, especially remarkable when comparing the simultaneous effect of $\mathrm{TiO}_{2}, \mathrm{O}_{3}$ and light with only photocatalysis and ozonation in the dark. By considering that $\mathrm{O}_{3}$ reacts very efficiently with aromatic compounds, they tested an ozonation pretreatment in the dark to perform the initial steps of aniline degradation, followed by photocatalysis. For this arrangement, the TOC reduction at the initial stages of photocatalysis was significantly increased with respect to photocatalysis without previous ozonation treatment. The opposite sequence of events (photocatalytic pretreatment followed by ozonation) did not appreciably increase the efficiency of aniline degradation. The combination of ozonation and photocatalysis with $\mathrm{TiO}_{2}$ leads to a larger TOC removal that, despite being more energy and material demanding, could be preferred from an applied point of view.

Tanaka et al. [74] found that treatment by ozonation prior to the photocatalytic one significantly increases the mineralization of water contaminants. Klare et al. [69] investigated the combination of $\mathrm{TiO}_{2}$-assisted photocatalysis and ozonation in the degradation of various stable nitrogen-containing substrates. Their experimental results indicate the occurrence of a synergistic effect between ozonation and photocatalysis. The enhanced degradation efficiency is attributed to the fact that ozonation produces hydrophilic intermediate compounds whose attack by electrophilic hydroxyl radicals leads faster to carbon dioxide.

Tanaka et al. [83] investigated also the applicability of the photocatalytic ozonation for treating a real wastewater with a high content of nitrogen compounds. They treated liquid bovine manure obtaining degradation curves whose shapes are similar to those obtained for model substances. By laboratory experiments, it was demonstrated that the combination of ozonation and photocatalysis is an efficient approach for the degradation of different nitrogen-containing organic compounds; this combination increased the mineralization efficiency as compared to water treatment by only ozonation. In spite of its higher energy and material demand, from an applied point of view, the combination of ozonation and photocatalysis is considered as an interesting alternative for wastewater treatment. They suggest that the energy demand of this combined process could be considerably decreased by the use of solar irradiation and in situ electrochemical $\mathrm{O}_{3}$ generation.

Moraes et al. [71] evaluated the efficiency of photocatalysis and ozonation processes, alone or combined, to minimize the environmental impact of textile effluents, mainly related to their high colouration and the presence of toxic and carcinogenic reactive dyes. The ozonation process was the less efficient since it promotes only partial decolouration, a small modification of the substrates and not a real degradation or mineralization. The photocatalytic process promotes a rapid decolouration and an effective TOC reduction. However, the best results were found for the simultaneous combined process, which allowed total decolouration and also the highest TOC reduction.

Wang et al. [84] determined the kinetic parameters for the decomposition of formic acid by photocatalysis, ozonation and their combination; the scheme of the used experimental system is reported in Fig. 2. They found that the decomposition rate by the combined system is larger than the sum of those by each of the two methods and, on this basis, they conclude that a synergistic effect appears when photocatalysis and ozonation are performed simultaneously. The same effect was found by Addamo et al. [85] when oxalate anion was mineralized in water at $\mathrm{pH} 10$. By applying the Langmuir-Hinshelwood kinetic model to the photoreactivity results, the values of the kinetic constant and of the equilibrium adsorption constant were determined. The kinetic constant of the photocatalytic reaction in the presence of ozone is higher than that obtained in the presence of oxygen only; moreover, the value of the adsorption constant of oxalate ion in the first case is three times higher than in the second one. The higher adsorption capacity of oxalate anion on the surface of the photocatalyst in the presence of ozone 


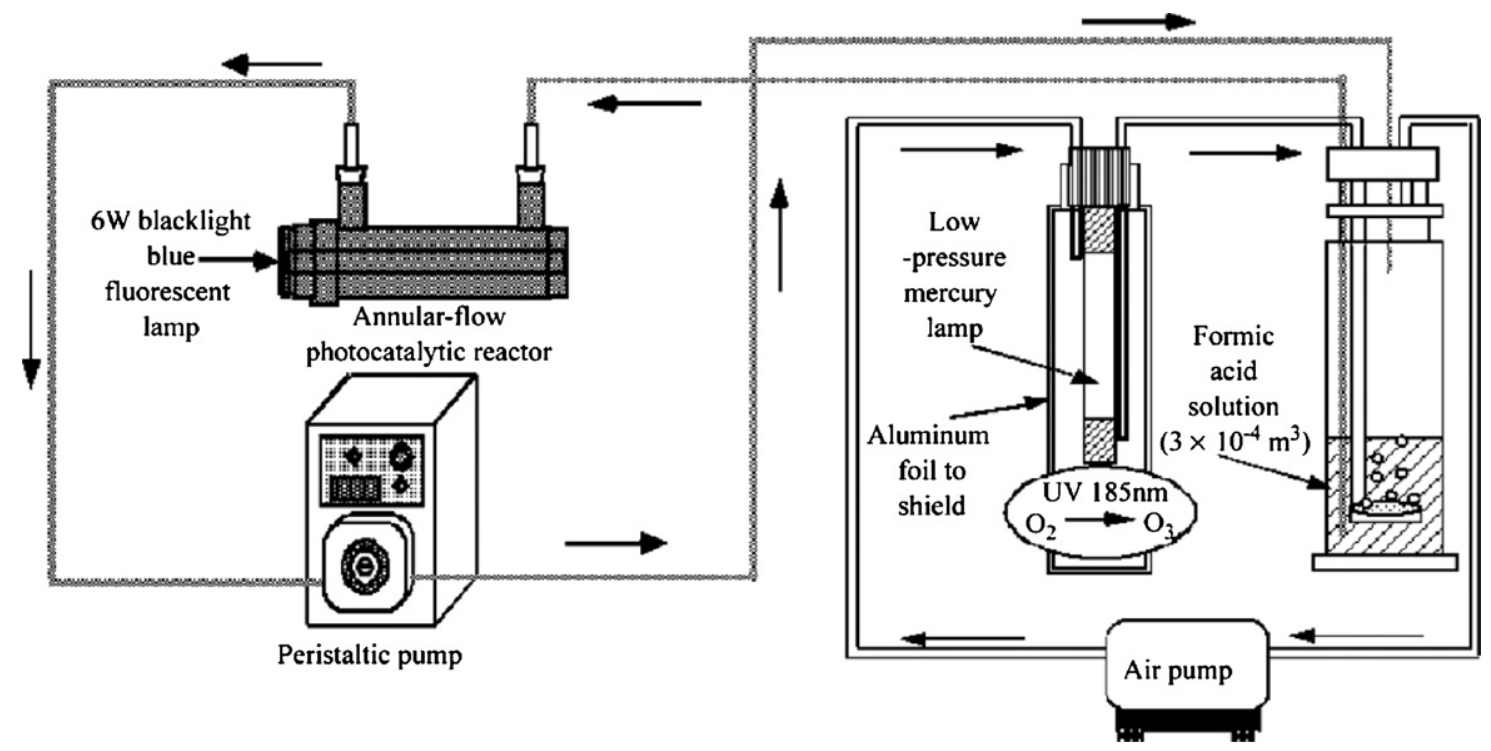

Fig. 2. Scheme of a reactor system for combined photocatalysis and ozonation in decomposition of formic acid [84].

and UV irradiation together with the fact that ozone is a more effective trap for the photogenerated electrons than oxygen can justify the important beneficial effect observed when photocatalysis and ozonation are contemporary used for the oxalate anion degradation.

The oxidation of free cyanide in aqueous suspensions of commercial $\mathrm{TiO}_{2}$ specimens has been carried out by contemporarily applying ozonation and photocatalysis [86]. Besides the photoreactivity experiments, Hernández-Alonso et al. [76,87] carried out EPR studies either in the dark or under UV-irradiation in order to gain information on the role played by ozone both in the increase of cyanide photooxidation rate and in the modification of the catalyst surface features. The reactivity results indicate that the disappearance of cyanide ions is determined by the occurrence of the following four routes: (i) the homogeneous reaction; (ii) the heterogeneous catalytic one; (iii) the heterogeneous photocatalytic one with oxygen; and (iv) the heterogeneous photocatalytic one with ozone. The kinetic modelling of reactivity results indicates that the presence of ozone plus radiation determines an increase of values of kinetic constants and of equilibrium adsorption constants. The equilibrium adsorption constant values in the presence of ozone without irradiation are higher than those obtained with pure oxygen under UV-illumination, indicating that ozone is able per se to modify the adsorption features of the catalyst surface.

By combining photocatalysis and ozonation, Li et al. [88] demonstrated the advantages of carbon black modified nano$\mathrm{TiO}_{2}\left(\mathrm{CB}-\mathrm{TiO}_{2}\right)$ thin films supported on $\mathrm{Al}$ sheets for removing catechol. The combined process considerably increased the TOC removal rate, and the kinetic study showed that the rate constants of the complete mineralization of catechol with $\mathrm{TiO}_{2} / \mathrm{UV} / \mathrm{O}_{3}$ are about two times higher than that of $\mathrm{UV} / \mathrm{O}_{3}$ with the same concentration of ozone. The $\mathrm{CB}-\mathrm{TiO}_{2}$ thin film was also used for degrading and mineralizing dibutylphtalate [89] by photocatalytic ozonation; also in this case, the degradation activity was higher than that showed by only photocatalysis.
Farré et al. [90] applied the photocatalytic ozonation to promote mineralization of water-soluble pesticides, such as alachlor, atrazine, chlorfenvinfos, diuron, isoproturon and pentachlorophenol. The application of the combined system leads to a rapid decrease of the concentration of these biorecalcitrant compounds and to a strong reduction of total organic carbon content, except for atrazine.

Agustina et al. [91] have carried out an exhaustive review of the most recent papers on the synergistic effect of photocatalysis and ozonation applied to wastewater treatment. This review focuses on the chemical effects of ozone dosage, $\mathrm{pH}$ and crystal composition of photocatalyst on the degradation rate of different pollutants. The authors also give valuable information on the compounds degraded by various researchers, the detected intermediates, the mechanism, the kinetics and the economic aspects related to the application of photocatalytic ozonation to the treatment of industrial wastewaters.

Heterogeneous photocatalysis is regarded as a promising technique for purifying indoor VOCs. However, the application of this method has been limited by the problem of deactivation of photocatalyst and of generation of refractory reaction intermediates. Shen and $\mathrm{Ku}$ [92] studied the decomposition of trichloroethylene in the gas phase by the $\mathrm{TiO}_{2}-\mathrm{UV}$ process in the presence of ozone. They found that the addition of ozone reduced the removal of TCE, possibly because excessive ozone molecules could scavenge hydroxyl radicals produced from the UV excitation of $\mathrm{TiO}_{2}$. Pengyi et al. [93] investigated the effect of added ozone on the photocatalytic oxidation of gaseous toluene, a VOC that can determine catalyst deactivation during photocatalytic oxidation [94]. In the absence of $\mathrm{O}_{3}$, toluene conversion drops rapidly at high toluene concentrations and the photocatalyst deactivates turning from white to brown. The addition of ozone avoids the photocatalyst deactivation. The influence of humidity on the photocatalytic oxidation with ozone was found to be complex: a little humidity improves the decomposition of toluene, 
while too much humidity depresses the decomposition. The authors explain that humidity enhances the contaminant decomposition by enhancing the generation of hydroxyl radicals but, at the same time, it hinders the contact of toluene with the photocatalyst and ozone and consequently it decreases the decomposition.

\section{Electrochemical treatment}

The high degree of recombination between photogenerated electrons and holes is sometimes a major limiting factor controlling photocatalytic efficiency [95]. The deposition of noble metals on $\mathrm{TiO}_{2}$ films can strongly hinder the electron-hole recombination by attracting photogenerated electrons and so it would improve the performance of photocatalytic processes. However, if the accumulated negative charges are not consumed or not further transferred out of the metal particles, photogenerated holes may be attracted by negatively charged metal particles, which become recombination centres [96]. It has been recently reported [97] that an anodic bias applied to a $\mathrm{TiO}_{2}$ film can not only spatially separate conduction band electrons but also drive away the photogenerated electrons accumulated on metal particles to another compartment of cell, reducing the electron-hole recombination and separating oxidation and reduction sites.

A hybrid technology consisting in the combination of noble metal deposition with the application of an external electric field was developed by He et al. [98] in order to improve the efficiency of photocatalytic degradation of formic acid on $\mathrm{Ag}-\mathrm{TiO}_{2}$ films. The combination of the Ag deposition and the application of anodic bias showed a beneficial effect not only in enhancing the formic acid oxidation rate but also the COD removal rate, which was higher than that of the pure photocatalytic process. The enhancement effect caused by the external electric field in the presence of $\mathrm{Ag}$ denotes that the deposited metal can not only trap the photogenerated electrons but also assist the external electric field to make them migrate from the $\mathrm{TiO}_{2}$ film anode to the counter-electrode in another compartment of the cell. Upon close examination of the kinetic constants of each process, it was found that the rate constant of photoelectrocatalysis with $\mathrm{Ag}-\mathrm{TiO}_{2}$ is a simple sum of those of photoelectrocatalysis on $\mathrm{TiO}_{2}$ and photocatalysis on $\mathrm{Ag}-\mathrm{TiO}_{2}$. Even if the combined method does not show a synergistic effect but only an additive one, the method is very valuable when there is the need for degradation of organic pollutants recalcitrant to electrochemical or photocatalytic treatments.

The main advantage of photoelectrocatalysis is its great versatility joined to the simplicity of the reactors in terms of construction and management (particularly suitable for automation) [99]. However, application at large scale is limited by the difficulty to find materials with specific characteristics to make the process competitive. Moreover, the oxidation in the potential region of water stability can lead to electrode fouling due to the formation of polymeric materials. $\mathrm{Ti} / \mathrm{PbO}_{2}, \mathrm{Ti} / \mathrm{SnO}_{2}, \mathrm{Ti} / \mathrm{IrO}_{2}$, glassy carbon are generally used as the materials, but some of them decrease their activity due to surface fouling (glassy carbon) or limited service life $\left(\mathrm{Ti} / \mathrm{IrO}_{2}\right)$.
Boron-doped diamond (BDD) [100,101], i.e., silicon coated by a layer of synthetic diamond heavily doped with boron in order to obtain acceptable electric conductivity, has been proposed as anode for the degradation of organic compounds [102]. The oxidation process at BDD anodes involves production of $\mathrm{HO}^{\bullet}$ radicals scarcely adsorbed at the BDD surface: they consequently desorb and can attack the organic pollutant. This means that $\mathrm{BDD}$ anode behaves like an $\mathrm{HO}^{\bullet}$ generator. Some refractory organic compounds present in water (phenol [103], 4-chlorophenol [104], surfactants [105], diuron and dichloroaniline [106], and triazines [107]) have been successfully treated by using BDD anodes. Moreover, BDD electrode has shown to be effective to oxidize cyanuric acid (CA, 2,4,6-tri-hydroxy-1,3,5triazine) [107], which is known to be refractory to most AOPs, including heterogeneous photocatalysis [108]. It was found that the best operating conditions to photooxidize CA in the electrochemical reactor are not the best ones to photooxidize the starting molecule (atrazine or some other triazine). In contrast, heterogeneous photocatalysis is effective to photodegrade atrazine and other triazine herbicides for which CA represents the final oxidation product [108]. An intriguing future possibility could be to couple heterogeneous photocatalysis with the electrochemical technology to perform a hybrid system for the photocatalytic degradation of atrazines, followed by the electrochemical oxidation of CA.

The photoelectro-Fenton method [109] complements photoFenton and electro-Fenton reaction. In the latter, a potential is applied between two electrodes immersed in a solution containing Fenton reagent and the target compound. The recent study of the herbicide 2,4,5-trichlorophenoxyacetic acid (2,4,5-T), performed in an undivided cell with a $\mathrm{Pt}$ anode and an $\mathrm{O}_{2}$-diffusion cathode, showed that the photoelectrochemical process was more powerful than the electro-Fenton process, which can yield only about $60-65 \%$ of decontamination. The electro-Fenton method provides complete destruction of all reaction intermediates, except oxalic acid, which in the presence of $\mathrm{Fe}^{3+}$ ions forms stable complexes that remain in the solution. The fast photodecarboxylation of such Fe(III)-oxalate complexes by UV light explains the highest oxidative ability of the photoelectro-Fenton treatment, which allows a fast and total mineralization of highly concentrated acidic aqueous solutions of 2,4,5-T at low current and temperature. A similar behaviour was found for the herbicide 3,6-dichloro-2-methoxybenzoic acid [110].

\section{Biological treatment}

The possibility to couple biological and photocatalytic methods has attracted the attention of many researchers in recent times. While photocatalysis is not specific (or almost not) for particular substrates, the biological method (which is the most common and cheapest process used for wastewater remediation) is not able to treat substances which are biorecalcitrant or bactericide. Substances used as herbicides (metobromuron, isoproturon, etc.) or in the manufacture of dyes, such as 5amino-6-methyl-2-benzimidazolone (AMBI) are biorecalcitrant molecules, while compounds, such as benzalkonium chloride are bactericides [111-114]. The combination of biological method 
with heterogeneous photocatalysis can be used to reduce the biorecalcitrance or the toxicity to bacteria to a level that permits the biological treatment. Therefore, the photocatalytic pretreatment is intended to modify the structure of the pollutants by transforming them into non-toxic and easily biodegradable intermediates. When the pretreatment is successful, the subsequent biological degradation is achieved in a shorter time and in a less-expensive way. For the coupled system, the phototreatment stage must be designed to obtain a solution biologically compatible after elimination of the initial biorecalcitrant compounds and their inhibitory intermediates. These requirements, and the information concerning the toxicity and the biodegradability evolution of the phototreated solution, allow one to determine the optimal time to stop the photocatalytic treatment before feeding the treated water to the biological reactor. This time corresponds to the best compromise between the efficiency of the phototreatment and its cost. The shortest phototreatment time is desired to avoid long irradiation times and the consequent high electrical consumption. This is important because electricity represents about $60 \%$ of the total operational cost of photocatalytic reactors [115]. However, if the fixed pretreatment time is too short, the intermediates remaining in solution could still be structurally similar to the initial biorecalcitrant compounds.

Reference [116] offers an overview of recent works (1998-2002) where photocatalytic and biological processes were coupled for wastewater treatment. All the 16 cases presented indicate the plausibility of using the coupled approach at pilot scale to treat real industrial wastewaters. This review confirms the beneficial effects of such two-step treatment at laboratory scale and signals the lack of studies carried at field scale with the same approach.

Parra et al. [117] performed laboratory experiments to study a new coupled system that employs $\mathrm{TiO}_{2}$ supported on glass rings in the photocatalytic reactor and bacteria supported on biolite in the biological part. The advantages of this system are that the catalyst can be reused and the $\mathrm{pH}$ of the solution remains at values between 6.0 and 6.5 , which are tolerable by the biomass. The coupled photochemical and biological reactor was employed to reach the complete mineralization of isoproturon, one of the most used herbicide. Besides laboratory experiments, Parra et al. [117] studied the efficiency of degradation by direct solar light and also the feasibility of coupling a compound parabolic collector with a biological system at pilot scale for treating real biorecalcitrant wastewater. The solar experiments were carried out at the Plataforma Solar de Almería (Spain) using natural sunlight irradiation. The coupled photocatalytic-biological flow reactor was operated in semicontinuous mode. The authors demonstrate the usefulness of the photocatalytic process preceding the biological one for the complete mineralization of a non-biodegradable organic substance. The photodegraded solution of isoproturon was biologically compatible and its complete mineralization was reached by biological means. The field experiments using solar collectors demonstrated that the solar photocatalytic treatment is effective for the purification of water contaminated by herbicides.

Parra et al. [117] proposed a general strategy to develop a combined system for biorecalcitrant wastewater treatment. The following points were taken into account: the biodegradability of the initial solutions, the operation mode of the coupled reactor, the chemical and biological characteristics of the phototreated solutions, the optimal conditions of both photochemical and biological processes, and the efficiency of the coupled reactor. This strategy was illustrated by case studies of four different pollutants: $p$-nitrotoluene-ortho-sulfonic acid (a pollutant coming from the manufacture of dyes, surfactants and brighteners), metobromuron (another widely used herbicide), isoproturon and 5-amino-6-methyl-2-benzimidazolone (a model compound of the dye industry). The authors stress the point that this strategy is not a universal solution and each effluent must be considered and tested separately. Chemical, biological and kinetic studies must be always carried out to ensure that the photochemical pretreatment increases the biocompatibility of the treated wastewater.

On this ground, Mohanty et al. [118] have coupled $\mathrm{TiO}_{2}$ based photocatalytic pretreatment with a conventional activated sludge process to achieve improvement in the biodegradation of 1-amino-8-naphthol-3,6-disulfonic acid, a contaminant of the textile industry. They carried out the photodegradation experiments at an optimized $\mathrm{TiO}_{2}$ content and determined the minimum pretreatment time required for transforming the recalcitrant contaminant and for achieving enhanced biodegradation.

\section{Membrane reactor}

$\mathrm{TiO}_{2}$ is the most often used photocatalyst due to its considerable activity, high stability, non-environmental impact and low cost. In photocatalytic processes, the $\mathrm{TiO}_{2}$ catalyst is generally applied in the form of powder suspended in slurry. The inconvenience of this kind of approach at large scale is the catalyst-recovering step from the solution at the end of operation. This problem can be solved immobilizing the catalyst on an inert surface, such as glass, quartz, concrete or ceramics. This configuration has its advantages and disadvantages. Due to the fact that fixation determines mass transfer limitations of pollutants to the surface of the catalyst [119] and also a loss of photocatalytic activity, slurry reactor systems excel the fixed ones with respect to photocatalytic degradation efficiency. However, as said, for slurry reactors, mainly for the continuous ones, the $\mathrm{TiO}_{2}$ particles have to be separated from the treated water at the exit from the detoxification process. Thus, for the development of the photocatalytic technology, the solid-liquid separation is an extremely important issue. The best possible recovery of $\mathrm{TiO}_{2}$ particles must be ensured in order to prevent a decrease of the catalyst concentration in the reactor system and to avoid the wash out of $\mathrm{TiO}_{2}$ particles causing a non-acceptable secondary pollution. The production process of $\mathrm{TiO}_{2}$ catalysts generates very fine powders. P25 Degussa has an average primary particle size of about $21 \mathrm{~nm}$ even if in aqueous media the particles form aggregates within the micron range. In this range of particle size, solid-liquid separation is influenced by interfacial effects of the aggregates rather than by the size of the primary particles.

The classical solid-liquid separation processes, such as sedimentation, flotation and membrane filtration may find, in principle, application in the separation of $\mathrm{TiO}_{2}$ particles from a liquid if the controlling parameters are optimized. From a practical point 
of view, however, the sedimentation of $\mathrm{TiO}_{2}$ after $\mathrm{pH}$ adjustment or the coagulation with flocculants like basic aluminium chloride is not satisfactory because the sedimentation is very long, lasting hours, and the supernatant needs to be filtered after the sedimentation step. Membrane filtration offers advantages and disadvantages. It is purely a physical separation process, which does not involve a phase change or interphase mass transfer, and may be used as a single step for the complete recovery of $\mathrm{TiO}_{2}$ particles from liquids. The major problems, when membrane separation is applied to powder photocatalyst recovery, are the great membrane flux decline and the membrane fouling.

In the field of membrane separation, microfiltration is a solid-liquid separation process useful when colloids and fine particles in the $0.1-5 \mu \mathrm{m}$ range are involved. In comparison with ultrafiltration, microfiltration offers the further advantages of needing relatively low transmembrane pressure for operation (usually $<300 \mathrm{kPa}$ ) and of providing a relatively high filtration rate with a consequent reduction of equipment and operating costs.

$\mathrm{Xi}$ and Geissen [120] investigated the possibility of catalyst separation from water by cross-flow microfiltration by using $\mathrm{TiO}_{2}$ suspensions and thermoplastic membranes. The effects of operating conditions, such as feed concentration, $\mathrm{pH}$ and ionic strength, cross-flow velocity and transmembrane pressure on the separation characteristics have been studied and the optimal conditions were established. An extreme sensitivity to $\mathrm{pH}$ and electrolyte concentration was observed. A higher steady state flux was obtained by determining the coagulation-flocculation state of $\mathrm{TiO}_{2}$ particles through the control of $\mathrm{pH}$ at values close to the isoelectric point and by adding specific electrolytes to the slurry.

Fu et al. [121] investigated the possibility of coupling photocatalysis and membranes for the degradation of fulvic acid.
They used a submerged membrane photocatalytic reactor with a nano-structured $\mathrm{TiO}_{2}$-silica gel photocatalyst; the scheme of this photoreactor is reported in Fig. 3. The catalyst particles were small enough to form a homogeneous suspension and big enough to easily settle while having the $\mathrm{TiO}_{2}$ with high activity. The microfiltration separation process allowed the $\mathrm{TiO}_{2}$ be easily separated, recovered and reused; more significantly, it was efficient to maintain high flux of membranes. In fact, the spherical ball-shaped particles improve the service life of microfiltration membrane by reducing fouling on surface; moreover, the particles do not deposit inside the pores preventing pore closure.

Doll and Frimmel [122] investigated the photocatalytic degradation of pharmaceutical and diagnostic residues in a pilot plant over a period of several days. The pilot plant consisted of a photocatalytic reactor followed by a cross-flow microfiltration module. A continuous operation of the pilot plant was achieved by a continuous separation and reuse of $\mathrm{TiO}_{2}$ with periodical back-washing operations of the filtration module. The investigation also included the testing of membrane materials because in this case the membrane must be resistant to abrasion and to periodical back-washing. A self-made tubular module with a ceramic single channel membrane of $\alpha$-aluminium oxide achieved the best cross-flow-membrane microfiltration because of its resistance to abrasion and back-washing. The photocatalytic activity of tested $\mathrm{TiO}_{2}$ powders was constant during the continuous usage over several days.

Recently, it has been demonstrated that the integration of heterogeneous photocatalysis with a separation process using a selective membrane, a process called pervaporation, is a very promising method to improve the detoxification efficiency of water streams containing organic pollutants at low concentration. The membrane plays both the roles of a simple barrier

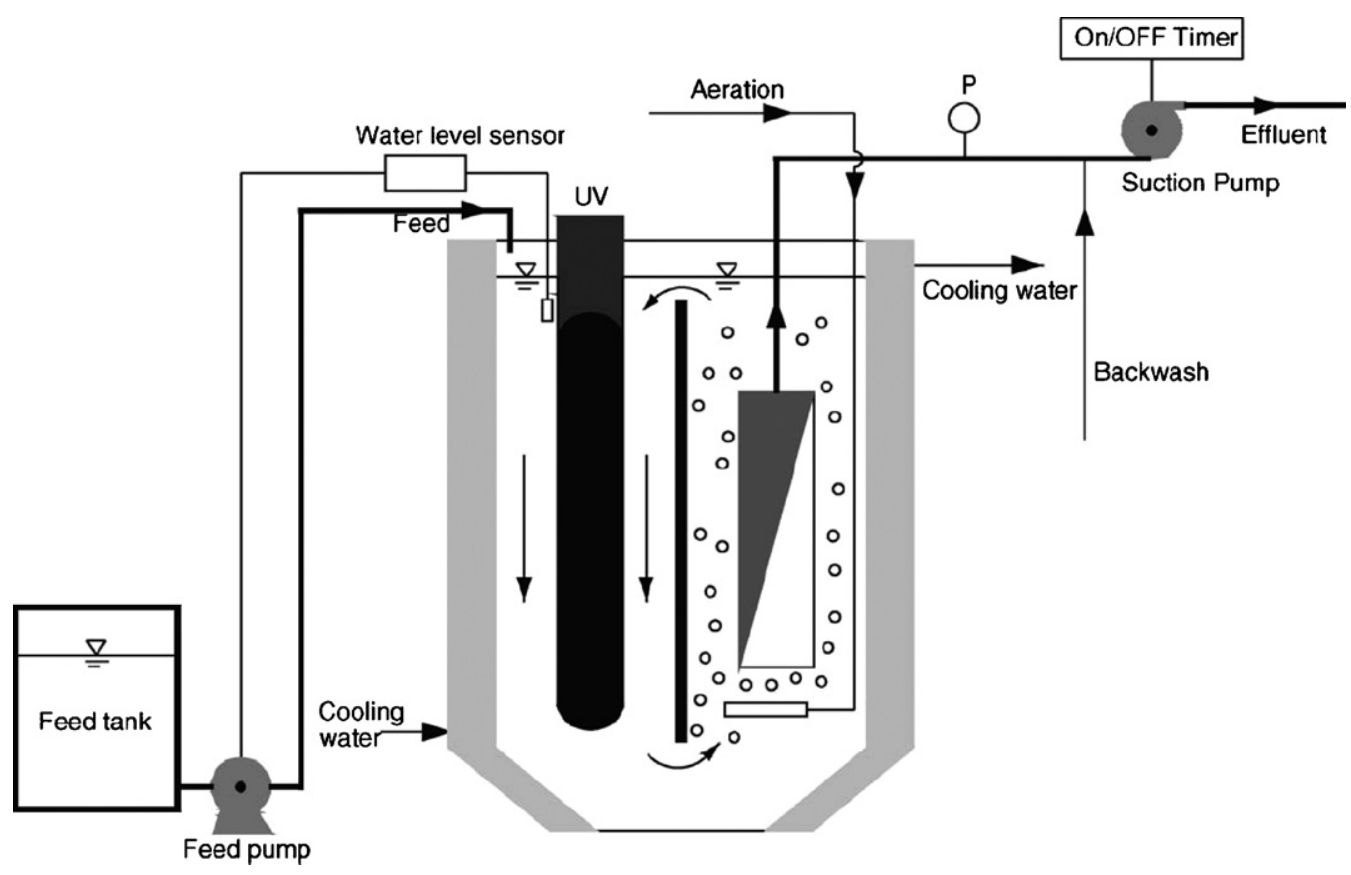

Fig. 3. Scheme of the submerged membrane photocatalytic reactor for fulvic acid removal [121]. 
for the catalyst and of a selective barrier for the molecules to be degraded. The commercial pervaporation membranes are organophilic so that most of the organic compounds permeate preferentially with respect to water. 4-Chlorophenol (4-CP) has been used as a probe molecule and the disappearance rate (transformation in hydroquinone, $\mathrm{HQ}$, and benzoquinone, $\mathrm{BQ}$ ) was highly improved [123]. A synergy was observed because photocatalysis is favoured by the continuous subtraction by pervaporation of the intermediates that otherwise would compete with 4-CP for photocatalytic oxidation. In addition, pervaporation takes advantage of photocatalysis, which transforms a poorly permeable compound (4-CP) into highly permeable compounds (HQ and especially $\mathrm{BQ}$ ). It is worth noting that in the integrated process the quantity of permeate stream collected is very small in respect to the initial volume of water to be purified.

Polymeric ultrafiltration membranes, such as polyacrylonitrile (PAN), FS50PP (fluoride + polypropylene) and GR51PP (polysulfone + polypropylene) have been used. They showed a good photostability checked by SEM and TOC and acceptable values of water permeate flux, but the rejection was unfortunately negligible. In order to improve the rejection effects, polymeric nano-filtration membranes have been tested [124-127]. The best ones were NF-PES-010 (a more permeable polyethersulfone, Hoechst) and N30F (a modified less permeable polysulfone, Hoechst). The choice of the membrane depends on the molecular size of the pollutants to be treated. The $\mathrm{pH}$ can influence very strongly the rejection as an electrostatic interaction, the Donnan exclusion phenomenon [128], may arise between the charged membrane and the ionic pollutant.

In addition to 4-nitrophenol (4-NP), degradation tests were successfully carried out on humic acids, phenol, benzoic acid, olive mill wastewater, organic dyes, drugs, etc. [127].

The selected membranes showed the capability to retain the photocatalyst and to reject partially organic species by controlling the residence time in the reacting system. Further work is required to look for other types of membranes, such as high rejection NF-type or low rejection reverse osmosis-type membranes, efficient also with pollutants of low molecular weight.
Some tests aimed to photodegrade lincomycin were carried out at the Plataforma Solar de Almería (Spain) [129] by using sunlight for irradiating batch or continuous systems; the corresponding schemes are reported in Fig. 4. It was noticed a total organic carbon accumulation in the reacting volume. This feature was explained by considering that under the used experimental conditions, the amount of photons entering the system per unit time were not sufficient to mineralize the organic carbon fed in the photoreactor per unit time.

In conclusion, it is possible to say for these systems that the proposed configuration arranged for working in continuous regime seems the most promising set-up for application because it takes the advantages of both the classical photoreactors (catalyst in suspension) and the membrane processes (separation at molecular level).

\section{Membrane photoreactor}

As reported in the previous section, an approach to immobilize photocatalytic powders is to combine a slurry with membrane filtration; in this system, membranes are used as a separating layer to retain the catalyst. A drawback of membrane reactors is that the use of photocatalytic powders determines that the reactants must diffuse to the catalyst surface before photocatalytic reactions can occur. This diffusion process is relatively slow and so it is likely to be a rate-determining step, especially for the case where reactants at low concentrations must be degraded. In order to solve this problem, a recent strategy was to utilize photocatalytic membranes with pores of several nano-meters in which the photocatalyst is capable not only of performing selective permeation but also of producing an oxidized permeate stream. In this configuration, oxidation by $\mathrm{HO}^{\bullet}$ radicals occurs both on the external surface of membrane and inside the pores, while reactants are permeating in a one-pass flow. The main advantage of membrane photoreactors [130] is that this configuration allows one to minimize the mass transfer resistances between the bulk of the fluid and the semiconductor surface. As a consequence of the forced transport of reactants by

\section{PFP 2}

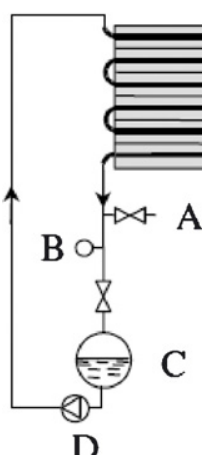

(a)

$\mathbf{H}$
PFP 1

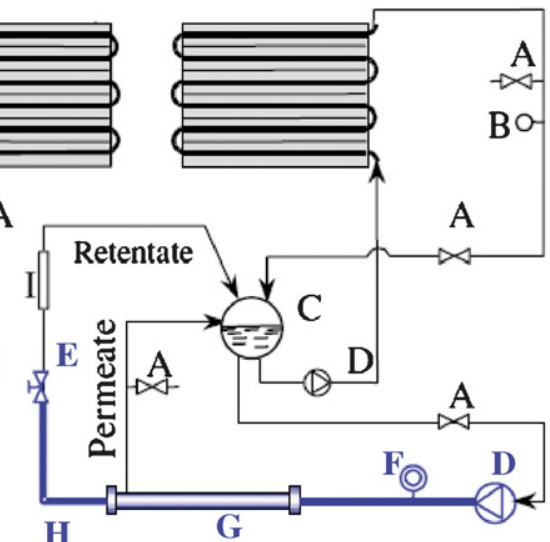

(b)

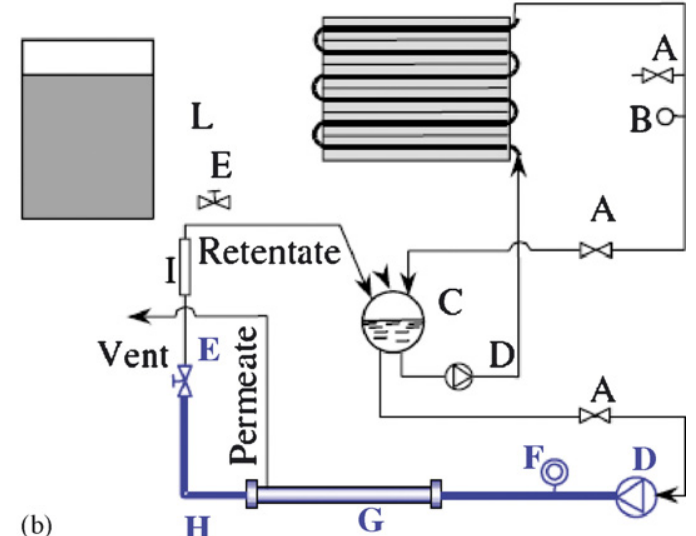

Fig. 4. Lincomycin degradation in a membrane reactor under sunlight irradiation. Scheme of the photoreacting batch systems (a) and of the photoreacting continuous system (b): (A) switch valve; (B) thermocouple; (C) not-reacting tank; (D) pump; (E) regulation valve; (F) manometer; (G) membrane vessel; (H) line under pressure; (I) rotameter; (L) feed tank; (PFP) plug flow photoreactor [129]. 
convection inside the pores, an increased reaction rate, compared with conventional diffusion transport, is observed.

Photocatalytic membrane reactors have been successfully applied to liquid phase reactions of trichloroethylene [131], 4-nitrophenol [132] and Methylene Blue [133].

Maira et al. [134] demonstrated that a photocatalytic membrane reaction system is effective for enhancing the gas phase photocatalytic oxidation of trichloroethylene using a nano-structured $\mathrm{TiO}_{2}$ membrane and a $\mathrm{TiO}_{2}$-zeolite hybrid membrane. It was found that the observed reaction rate increased for the case of photocatalytic membrane reaction with respect to the case of conventional reaction configurations in liquid phase [131] and gas phase reaction [135].

Tsuru et al. [135] investigated $\mathrm{TiO}_{2}$ membranes having pore sizes of several nano-meters for use in the photocatalytic reaction of methanol in the gas phase. Porous $\mathrm{TiO}_{2}$ membranes were prepared by coating colloidal $\mathrm{TiO}_{2}$ sols on the outer surface of cylindrical $\alpha$-alumina microfiltration membranes. The photocatalytic decomposition with membrane permeation showed a larger rate than the case without membrane permeation, this case corresponding to a conventional photocatalytic reactor composed of a thin $\mathrm{TiO}_{2}$ film prepared on non-porous substrates. For the case with membrane permeation, all reactants were required to permeate through $\mathrm{TiO}_{2}$ pores, providing a more effective contact between the reactants and the catalytically active $\mathrm{TiO}_{2}$ surface; in fact, the transport of organic compounds to the $\mathrm{TiO}_{2}$ surface was enhanced by forced convection in addition to transport by diffusion, and a larger surface area was utilized for the photocatalytic reaction.

Tsuru et al. [136] prepared porous $\mathrm{TiO}_{2}$ membranes by the sol-gel process and applied them for the gas phase reaction of methanol and ethanol. In an attempt to increase the photocatalytic activity, they also modified the $\mathrm{TiO}_{2}$ membrane with platinum. Under the used experimental conditions, methanol at a $100 \mathrm{ppm}$ feed was completely photooxidized by black light irradiation; at higher concentrations, the conversion decreased. $\mathrm{TiO}_{2}$ platinization caused both photocatalysis as well as thermal catalytic reactions. In the degradation of ethanol, a synergistic effect between photocatalysis and thermal catalytic reactions was observed [137]. The overall ethanol conversion over illuminated Pt-modified $\mathrm{TiO}_{2}$ was larger than the sum of the conversions for photocatalysis and thermal catalytic reactions; the synergistic effect was attributed to the photoproduction of acetaldehyde on $\mathrm{TiO}_{2}$ and its subsequent thermal oxidation over platinum.

\section{Physical adsorption}

Even if heterogeneous photocatalytic processes have shown to be very effective, there are many real situations they cannot cope with. The pollutants are frequently present in concentrations that are too low to allow their efficient removal; moreover, natural organic matter present in water can occupy the catalytically active surface sites causing much lower degradation efficiency. In order to overcome the above-mentioned problems [138-140], the photocatalytic oxidation has been coupled with physical adsorption. In this combination, a suitable adsorbent, such as silica, alumina, zeolites, clays or activated carbon (AC), selectively adsorbs the toxic pollutants without extracting the natural compounds present in the water. Once the adsorbent losses its capacity of removing the contaminant organics, it is separated from the purified water and it is mixed with $\mathrm{TiO}_{2}$ powder in water to produce a composite suspension. The desorbing component is therefore photocatalytically oxidized by irradiating the suspension and the regenerated adsorbent can be reused in further adsorption cycles. The other alternative of photocatalysis-adsorption combination consists in fixing the catalyst on the surface of the adsorbent, thereby producing a catalyst-adsorbent system with advantageous features, such as better separability or better aggregation properties. In this case, the adsorption and oxidation of organic compounds occur continuously, thus avoiding the need of cyclic operations.

Matos et al. [140] aimed to detect any associative or synergistic effect between powdered $\mathrm{TiO}_{2}$ and powdered $\mathrm{AC}$ maintained in an aqueous suspension. The mere addition of $\mathrm{AC}$ to $\mathrm{TiO}_{2}$ suspension was expected to induce some beneficial effect because of the high adsorption capacity of $\mathrm{AC}$ with respect to organic molecules. The authors observed that depositing $\mathrm{TiO}_{2}$ by different ways on different supports induces some doping by foreign ions penetrating the $\mathrm{TiO}_{2}$ lattice during the final thermal treatment necessary for the stabilization of the material. To better put in evidence any synergistic effect, a mechanical mixture of $\mathrm{AC}$ and $\mathrm{TiO}_{2}$ was tested, therefore preserving the initial surface state of each solid constituent. The chosen test reaction was the photocatalytic degradation of phenol. From experiments of phenol adsorption, they observed no additivity of the adsorption capacity of both solids when they are mixed. This difference was ascribed to a strong interaction between titania particles and $\mathrm{AC}$, which creates an intimate interface non-accessible to phenol molecules from the solution. From the reactivity runs, it was observed that the photocatalytic activity of the $\mathrm{TiO}_{2}-\mathrm{AC}$ system is higher than that of neat $\mathrm{TiO}_{2}$. The addition of $\mathrm{AC}$ to $\mathrm{TiO}_{2}$ creates a kinetic synergistic effect in phenol disappearance with an increase of the rate constant by a factor of 2.5 . Phenol molecules, adsorbed and accumulated on AC, are able to be transferred to titania where they are decomposed under irradiation; this transfer occurs through the $\mathrm{TiO}_{2} / \mathrm{AC}$ interface with the concentration gradient acting as the driving force. In order to confirm this explanation, the mechanical mixture of $\mathrm{TiO}_{2}$ and $\mathrm{AC}$ was modified by two physical treatments: grinding and sonication. Grinding had practically no effect upon phenol adsorption but slightly lowered the photocatalytic activity; grinding may produce defects in the $\mathrm{TiO}_{2}$ lattice that would behave as electron-hole recombination centres, worsening the photocatalytic activity. On the contrary, sonication of the mixture was detrimental for the photoreactivity; sonication favours the separation of titania and AC particles, thus partly destroying their surface interaction. The even partial destruction of this interface stops the transfer of adsorbed molecules, and then the synergistic effect disappears.

Herrmann et al. [141] confirmed, in solar application and in a large scale, the synergistic effect obtained with powdered $\mathrm{TiO}_{2}$ and powdered AC maintained in an aqueous suspended mixture. The test reaction was the 4-chlorophenol degradation. The addition of a commercial $\mathrm{AC}$ to $\mathrm{TiO}_{2}$ under $\mathrm{UV}$ irradiation induced a 
synergistic effect by a factor of 2.4 in the photoefficiency of the photocatalyst. As for phenol photodegradation, the synergy was explained by an important adsorption of 4-CP on AC followed by a mass transfer to photoactive $\mathrm{TiO}_{2}$. This transfer occurred mainly via a 4-CP spillover induced by a mere mixture of both phases in suspension.

Ilisz et al. [142] studied the applicability of sequential operations of adsorption on an organo-clay and $\mathrm{TiO}_{2}$-based photocatalysis as a potential technology for water treatment. 2-Chlorophenol (2-CP) was chosen as model compound to test the efficiency of the combination. In particular, it was checked if the adsorbent has some negative effect on the photocatalytic process; in fact, the clay could show a shielding effect for the $\mathrm{UV}$ absorption of $\mathrm{TiO}_{2}$ and the desorption process of 2-CP could cause a lower degradation efficiency. In the combined system, the clay firstly adsorbed the 2-CP and then it was separated, dried and dispersed in aqueous $\mathrm{TiO}_{2}$ suspension. It was found that the rate of photocatalytic decomposition of 2-CP adsorbed on the organo-clay was practically the same as that without the adsorbent and much faster than that for direct photolysis at the same irradiation conditions $(\lambda>310 \mathrm{~nm})$. There was not significant difference in product distribution between the $2-\mathrm{CP} / \mathrm{UV} / \mathrm{TiO}_{2}$ and $2-\mathrm{CP} / \mathrm{clay} / \mathrm{UV} / \mathrm{TiO}_{2}$ systems and, moreover, it was found that the 2-CP/clay/UV/ $/ \mathrm{TiO}_{2}$ system did not exhibit changes in the total organic carbon content after completing the oxidation of all the organics. This fact indicates that no adsorbent damage is caused by the photocatalytic process and the adsorbent can therefore be reused in several treatment cycles.

Ilisz et al. [143] tested three different catalyst-adsorbent systems: (i) $\mathrm{TiO}_{2}$ intercalated into the interlamellar space of an untreated montmorillonite; (ii) $\mathrm{TiO}_{2}$ crystallized on hexadecylpyridinium chloride-treated montmorillonite; and (iii) hexadecylpyridinium chloride-treated montmorillonite as adsorbent and P25 Degussa $\mathrm{TiO}_{2}$ as photocatalyst. The most advantageous situation was found for the last case, for which the highest rate of 2-CP degradation was measured, no negative effect of the suspended adsorbent was observed and the recovered adsorbent was reused without further regeneration. For cases (i) and (ii), a considerably lower pollutant degradation rate was observed. In case (ii), the modest degradation was accompanied by a high decrease in the TOC content indicating that oxidation of the organic modifier took place continuously in the course of the photocatalytic process, damaging the adsorbent probably for the adjacency of the $\mathrm{TiO}_{2}$ particles and the alkyl chains. The low efficiency measured for case (i) was probably caused by the low crystallinity and small size (high band gap) of the produced $\mathrm{TiO}_{2}$ particles.

The photocatalysis-adsorption combination has been also used for destroying volatile organic compounds present in air. Ao and Lee [144] studied toluene vapour and nitrogen oxide removal using $\mathrm{TiO}_{2}$ immobilized on an activated carbon filter. Shiraishi et al. [145], by combining photocatalysis with adsorption and thermal regeneration, developed a novel air-purification system consisting of a rotating honeycomb loaded with zeolite or activated carbon, combined with a photoreactor able to eventually oxidize the desorbed volatile contaminants. Chin et al. [146] developed a kinetic model for a rotating adsorbent-photocatalyst reactor able to remove formaldehyde in air. Vapour formaldehyde was adsorbed from a simulated room onto a slowly rotating honeycomb that then passed through a small chamber in which locally recirculated heated air desorbed the formaldehyde and carried it through a photocatalytic reactor where the desorbed formaldehyde was oxidized. The regenerated adsorbent then rotated back into the airtight chamber. The advantages of this combination are that it allows rapid air contaminant removal followed by desorption into a small volume photoreactor where the consequent increase in contaminant concentration allows the use of a reactor smaller than a photocatalyst-only system would require. The model developed by Chin et al. [146] provides a technique for evaluating all the numerical parameters of the system, i.e. the adsorption, desorption and reaction rate constants, as well as the adsorption equilibrium constants, and so it can be applied to correctly design systems with different adsorption/desorption temperatures, adsorbent materials and chamber sizes.

\section{Conclusions}

Heterogeneous photocatalysis is a very powerful AOP able to destroy a great variety of organic and inorganic contaminants present in water and air. This system works only if a semiconductor oxide is irradiated by band gap radiation; this implies that for the operation of this system it is necessary to furnish photons to the catalyst.

Actually, the main drawback of this technology is represented by the fact that the quantum efficiency values are very low, only reaching $1 \%$ in the best conditions, i.e., only one over one hundred of the incident photons is able to produce an oxidation/reduction step. Depending on the amount of the contaminant present in the waste to be treated and on the needed degree of oxidation, it is necessary to provide the photoreacting system with a photon flow two orders of magnitude higher than that eventually utilized. Generally, the compounds in a specific contaminated air are very few and they are present at very low concentrations; moreover, the volumes to be treated are small, like those of freezing chambers, chambers for surgery, air conditioning in buildings, chambers for special production, etc. In this case, it is likely that heterogeneous photocatalysis can achieve the complete purification of the gaseous body. The opposite situation occurs in contaminated aqueous bodies where the contaminants vary in their chemical nature, and are probably at high concentrations and in high volumes. As a consequence, the photon flow needed for the treatment is amazingly huge.

Lamps can provide the necessary photons but the cost of photon production must be taken into account in the whole economics of the process and it can be very high. Sun can also give photons but only ca. $5 \%$ (ca. $30 \mathrm{~W} \mathrm{~m}^{-2}$ ) can be used by $\mathrm{TiO}_{2}$, and this cannot satisfy the needs of the treatment in a realistic way.

On the basis of the previous considerations, we think that the use of photocatalysis for wastewater remediation should be successful if addressed only to the transformation of recalcitrant to non-recalcitrant compounds, which subsequently can be easily degraded by conventional techniques. In this circumstance, 
the coupling of photocatalysis with other chemical and physical operations seems a good strategy to achieve the remediation goal.

Which would be the best combination? The authors believe that the answer to this question depends on the particular problem to be solved, and that any of the presented combination shows neither intrinsic advantages nor drawbacks that favour or exclude its utilization. Thus, for each system, treatability test must be done to find the best technology.

In conclusion, the combination of heterogeneous photocatalysis with chemical and physical operations appears to be the most promising tool for developing real applications of decontamination processes. However, by examining the literature on this topic, the authors noticed that almost the totality of experimental works have been carried out in artificial systems containing only one compound used as model molecule. It would be of a great importance to investigate real wastewater containing compounds of different chemical nature in order to elucidate the mutual effects of these compounds on their degradation rate.

The use of sunlight should be the final objective for some of the applications, but for achieving this goal, a systematic investigation on bench scale by using artificial light is needed in order to have a better knowledge of the influence of physicochemical and operational parameters on the photoreactivity.

\section{Acknowledgments}

M.I.L. thanks Comisión Nacional de Energía Atómica P5-PID-36-4 Program, PICT03-13-13261 ANPCyT and PIPCONICET 5472 from Argentina for funding. V.A. and L.P. thanks "Ministero dell'Università e della Ricerca Scientifica e Tecnologica" (Rome) for financially supporting this work.

\section{References}

[1] A. Vogelpohl, S.M. Kim, J. Ind. Eng. Chem. 10 (2004) 33-40.

[2] P.R. Gogate, A.B. Pandit, Adv. Environ. Res. 8 (2004) 501-551.

[3] P.R. Gogate, A.B. Pandit, Adv. Environ. Res. 8 (2004) 553-597.

[4] O.R. Legrini, E. Oliveros, A.M. Braun, Chem. Rev. 93 (1993) 671698.

[5] M.R. Hoffmann, S.T. Martin, W. Choi, D. Bahnemann, Chem. Rev. 95 (1995) 69-96.

[6] M. Schiavello (Ed.), Heterogeneous Photocatalysis, vol. 3. Wiley Series in Photoscience and Photoengineering, John Wiley \& Sons, Chichester, 1997.

[7] A. Fujishima, T.N. Rao, D.A. Tryk, J. Photochem. Photobiol. C: Photochem. Rev. 1 (2000) 1-21.

[8] K.S. Suslik (Ed.), Ultrasound: Its Chemistry, Physical and Biological Effects, VCH Publishers, New York, 1998.

[9] A. Kotronarou, G. Mills, M.R. Hoffmann, J. Phys. Chem. 95 (1991) 3630-3638.

[10] N. Serpone, P. Colarusso, Res. Chem. Intermed. 20 (1994) 635-679.

[11] P. Theron, P. Pichat, C. Pétrier, C. Guillard, Water Sci. Technol. 44 (2001) 263-270.

[12] V. Ragaini, E. Selli, C.L. Bianchi, C. Pirola, Ultrason. Sonochem. 8 (2001) 251-258.

[13] N.L. Stock, J. Peller, K. Vinodgopal, P.V. Kamat, Environ. Sci. Technol. 34 (2000) 1747-1750.

[14] I.Z. Shirgaonkar, A.B. Pandit, Ultrason. Sonochem. 2 (1998) 53-61.

[15] P. Theron, P. Pichat, C. Guillard, C. Pétrier, T. Chopin, Phys. Chem. Chem. Phys. 1 (1999) 4663-4668.
[16] J. Peller, O. Wiest, P.V. Kamat, Environ. Sci. Technol. 37 (2003) 1926-1932.

[17] E. Selli, Phys. Chem. Chem. Phys. 4 (2002) 6123-6128.

[18] M. Mrowetz, C. Pirola, E. Selli, Ultrason. Sonochem. 10 (2003) 247-254.

[19] Y.C. Chen, A.V. Vorontsov, P.G. Smirniotis, Photochem. Photobiol. Sci. 2 (2003) 694-698.

[20] L. Davydov, E.P. Reddy, P. France, P.G. Smirniotis, Appl. Catal. B: Environ. 32 (2001) 95-105.

[21] N. Serpone, R. Terzian, H. Hidaka, E. Pelizzetti, J. Phys. Chem. 98 (1994) 2634-2640.

[22] L. Davydov, P.G. Smirniotis, J. Catal. 191 (2000) 105-115.

[23] K.S. Suslick, Science 247 (1990) 1439-1445.

[24] J.N. Jensen, Hazard. Ind. Wastes 28 (1996) 265.

[25] C. Guillard, P. Théron, P. Pichat, C. Pétrier, Water Res. 36 (2002) 4263-4272.

[26] A. Mills, C.E. Holland, R.H. Davies, D. Worsley, J. Photochem. Photobiol. A: Chem. 83 (1994) 257-263.

[27] A.J. Johnston, P. Hocking, ACS Symp. Ser. 518 (1993) 106-118.

[28] T.J. Mason, J.L. Luche, Chemistry Under Extreme or Non-classical Conditions, John Wiley \& Sons, New York, 1997, p. 317.

[29] Y. Xu, C.H. Langford, J. Phys. Chem. 99 (1995) 11501-11507.

[30] Y. Xu, C.H. Langford, J. Phys. Chem. 101 (1997) 3115-3121.

[31] E.P. Reddy, L. Davydov, P. Smirniotis, Appl. Catal. B: Environ. 42 (2003) $1-11$.

[32] K.S. Suslick, S.J. Doktycz, E.B. Flint, Ultrasonics 28 (1990) 280-286.

[33] A.J. Hoffman, E.R. Carraway, M.R. Hoffmann, Environ. Sci. Technol. 28 (1994) 776-785.

[34] T. Wu, G. Liu, J. Zhao, H. Hidaka, N. Serpone, J. Phys. Chem. B 103 (1999) 4862-4867.

[35] M. Bertelli, E. Selli, Appl. Catal. B: Environ. 52 (2004) 205-212.

[36] E. Selli, C.L. Bianchi, C. Pirola, M. Bertelli, Ultrason. Sonochem. 12 (2005) 395-400.

[37] L.W. Kang, M.R. Hoffmann, Environ. Sci. Technol. 32 (1998) 3194-3199.

[38] L.W. Kang, H.M. Kung, A. Lin, M.R. Hoffmann, Environ. Sci. Technol. 33 (1999) 3199-3205.

[39] J. Yano, J.-I. Matsuura, H. Ohura, S. Yamasaki, Ultrason. Sonochem. 12 (2005) 197-203.

[40] T. Velegraki, I. Poulios, M. Charalabaki, N. Kalogerakis, P. Samaras, D. Mantzavinos, Appl. Catal. B: Environ. 62 (2006) 159-168.

[41] H. Harada, Ultrason. Sonochem. 8 (2001) 55-58.

[42] H. Harada, C. Hosoki, A. Kudo, J. Photochem. Photobiol. A: Chem. 141 (2001) 219-224.

[43] H. Harada, C. Hosoki, M. Ishikane, J. Photochem. Photobiol. A: Chem. 160 (2003) 11-17.

[44] C.P. Huang, C. Dong, Z. Tang, Waste Manag. 13 (1993) 361-377.

[45] C. Walling, Acc. Chem. Res. 8 (1975) 121-125.

[46] V. Augugliaro, E. Davì, L. Palmisano, M. Schiavello, A. Sclafani, Appl. Catal. 65 (1990) 101-116.

[47] M.I. Litter, Appl. Catal. B: Environ. 23 (1999) 89-114.

[48] P.A. Babay, C.A. Emilio, R.E. Ferreyra, E.A. Gautier, R.T. Gettar, M.I. Litter, Water Sci. Technol. 44 (2001) 179-185.

[49] C.A. Emilio, R.T. Gettar, M.I. Litter, J. Appl. Electrochem. 35 (2005) 733-740.

[50] N. Quici, M.E. Morgada, G. Piperata, P. Babay, R.T. Gettar, M.I. Litter, Catal. Today 101 (2005) 253-260.

[51] C.A. Emilio, W.F. Jardim, M.I. Litter, H.D. Mansilla, J. Photochem. Photobiol. A: Chem. 151 (2002) 121-127.

[52] D. Hufschmidt, D. Bahnemann, J.J. Testa, C.A. Emilio, M.I. Litter, J. Photochem. Photobiol. A: Chem. 148 (2002) 223-231.

[53] C. Baeza, A. Rossner, W.F. Jardim, M.I. Litter, H.D. Mansilla, Environ. Technol. 24 (2003) 1277-1281.

[54] O. Abida, C.A. Emilio, N. Quici, R.T. Gettar, M.I. Litter, G. Mailhot, M. Bolte, Water Sci. Technol. 49 (2004) 123-128.

[55] O. Abida, G. Mailhot, M. Litter, M. Bolte, Photochem. Photobiol. Sci. 4 (2006) 395-402.

[56] A.-G. Rincón, C. Pulgarin, Appl. Catal. B: Environ. 63 (2006) 222-231.

[57] J.-M. Herrmann, C. Guillard, P. Pichat, Catal. Today 17 (1993) 7-20. 
[58] W.H. Glaze, J.W. Kang, D.H. Chapin, Ozone Sci. Eng. 9 (1987) 335-352.

[59] J. Hoigné, H. Bader, Water Res. 10 (1976) 377-386.

[60] J. Hoigné, H. Bader, Water Res. 17 (1983) 173-183.

[61] B. Legube, V. Karpel, N. Leitner, Catal. Today 53 (1999) 61-72.

[62] W.H. Glaze, F.J. Beltrán, T. Tuhkanen, J.W. Kang, Water Pollut. Res. J. Canada 27 (1992) 23-42.

[63] M.D. Gurol, A. Akata, AIChE J. 42 (1996) 3283-3292.

[64] G.R. Peyton, W.H. Glaze, Environ. Sci. Technol. 22 (1988) 761-767.

[65] S. Chiron, A. Fernández-Alba, A. Rodríguez, E. García-Calvo, Water Res. 34 (2000) 366-377.

[66] L. Sánchez, X. Domènech, J. Casado, J. Peral, Chemosphere 50 (2003) 1085-1093.

[67] M. Prados, H. Paillard, P. Roche, Ozone Sci. Eng. 17 (1995) 183-194.

[68] S. Preis, S. Kamenev, J. Kallas, R. Munter, Ozone Sci. Eng. 17 (1995) 399-418.

[69] M. Klare, G. Waldner, R. Bauer, H. Jacobs, J.A.C. Broekaert, Chemosphere 38 (1999) 2013-2027.

[70] P. Kopf, E. Gilbert, S.H. Eberle, J. Photochem. Photobiol. A: Chem. 136 (2000) 163-168.

[71] S.G. Moraes, R.S. Freire, N. Durán, Chemosphere 40 (2000) 369-373.

[72] Y. Maeda, A. Fujishima, K. Honda, J. Electrochem. Soc. 128 (1981) 1731-1734.

[73] K.M. Bulanin, J.C. Lavalley, A.A. Tsyganenko, Colloid Surf. A 101 (1995) 153-158.

[74] K. Tanaka, K. Abe, T. Hisanaga, J. Photochem. Photobiol. A: Chem. 101 (1996) 85-87.

[75] K. Okamoto, Y. Yamamoto, H. Tanaka, M. Tanaka, A. Itaya, Bull. Chem. Soc. Jpn. 58 (1985) 2015-2022.

[76] M.D. Hernández-Alonso, J.M. Coronado, A.J. Maira, J. Soria, V. Loddo, V. Augugliaro, Appl. Catal. B: Environ. 39 (2002) 257-267.

[77] B. Kasprzyk-Hordern, M. Ziólek, J. Nawrocki, Appl. Catal. B: Environ. 46 (2003) 639-669.

[78] E. Gilbert, Ozone Sci. Eng. 24 (2002) 75-82.

[79] L. Ilisz, A. Bokros, A. Dombi, Ozone Sci. Eng. 26 (2004) 585-594.

[80] P. Pichat, L. Cermenati, A. Albini, D. Mas, H. Delprat, C. Guillard, Res. Chem. Int. 26 (2000) 161-170.

[81] T.S. Muller, Z. Sun, G.M.P. Kumar, K. Itoh, M. Murabayashi, Chemosphere 36 (1998) 2043-2055.

[82] L. Sánchez, J. Peral, X. Domènech, Appl. Catal. B: Environ. 19 (1998) 59-65.

[83] K. Tanaka, K. Abe, C.Y. Sheng, T. Hisanaga, Environ. Sci. Technol. 26 (1992) 2534-2536.

[84] S. Wang, F. Shiraishi, K. Nakano, Chem. Eng. J. 87 (2002) 261-271.

[85] M. Addamo, V. Augugliaro, E. García-López, V. Loddo, G. Marcì, L. Palmisano, Catal. Today 107-108 (2005) 612-618.

[86] E. Piera, J.C. Calpe, E. Brillas, X. Doménech, J. Peral, Appl. Catal. B: Environ. 27 (2000) 169-177.

[87] M.D. Hernández-Alonso, J.M. Coronado, J. Soria, J.C. Conesa, V. Loddo, M. Addamo, V. Augugliaro, Res. Chem. Interm. 33 (2007) 205-224.

[88] L. Li, W. Zhu, P. Zhang, Z. Chen, W. Han, Water Res. 37 (2003) 3646-3651.

[89] L. Li, W. Zhu, L. Chen, P. Zhang, Z. Chen, J. Photochem. Photobiol. A: Chem. 175 (2005) 172-177.

[90] M.J. Farré, M.I. Franch, S. Malato, J.A. Ayllón, J. Peral, X. Doménech, Chemosphere 58 (2005) 1127-1133.

[91] T.E. Agustina, H.M. Ang, V.K. Vareek, J. Photochem. Photobiol. C: Photochem. Rev. 6 (2005) 264-273.

[92] Y.S. Shen, Y. Ku, Chemosphere 46 (2002) 101-107.

[93] Z. Pengyi, L. Fuyan, Y. Gang, C. Qing, Z. Wanpeng, J. Photochem. Photobiol. A: Chem. 156 (2003) 189-194.

[94] G. Marcì, M. Addamo, V. Augugliaro, S. Coluccia, E. García-López, V. Loddo, G. Martra, L. Palmisano, M. Schiavello, J. Photochem. Photobiol. A: Chem. 160 (2003) 105-114.

[95] M.A. Fox, ChemTech 22 (1992) 680-685.

[96] H. Hidaka, Y. Asai, J. Zhao, K. Nohara, E. Pelizzetti, N. Serpone, J. Phys. Chem. 99 (1995) 8244-8248.

[97] Y. Li, G. Lu, S. Li, Appl. Catal. A: Gen. 214 (2001) 179-185.

[98] C. He, Y. Xiong, X. Zhu, Thin Solid Films 422 (2002) 235-238.
[99] K. Rajeshwar, J. Ibañez, Fundamentals and Applications in Pollution Abatement, Academic Press, New York, 1997.

[100] F. Beck, H. Krohn, W. Kaiser, M. Fryda, C.P. Klages, L. Schafer, Electrochim. Acta 44 (1998) 525-532.

[101] V. Fisher, D. Gandini, S. Laufer, E. Blank, C. Comninellis, Electrochim. Acta 44 (1998) 521-524.

[102] M. Panizza, P.A. Michaud, G. Cerisola, C. Comninellis, Electrochem. Commun. 3 (2001) 336-339.

[103] J. Iniesta, P.A. Michaud, M. Panizza, G. Cerisola, A. Aldaz, C. Comninellis, Electrochim. Acta 46 (2001) 3573-3578.

[104] M.A. Rodrigo, P.A. Michaud, I. Duo, M. Panizza, G. Cerisola, C. Comninellis, J. Electrochem. Soc. 148 (2001) D60-D64.

[105] G. Lissens, J. Pieters, M. Verhaege, L. Pinoy, W. Verstraete, Electrochim. Acta 48 (2003) 1655-1663.

[106] A.M. Polcaro, M. Mascia, S. Palmas, A. Vacca, Electrochim. Acta 49 (2004) 649-656.

[107] A.M. Polcaro, A. Vacca, M. Mascia, S. Palmas, Electrochim. Acta 50 (2005) 1841-1847.

[108] C. Minero, G. Mariella, V. Maurino, E. Pelizzetti, Langmuir 16 (2000) 2632-2641.

[109] B. Boye, M.M. Dieng, E. Brillas, J. Electroanal. Chem. 557 (2003) $135-146$.

[110] E. Brillas, M.A. Baños, J.A. Garrido, Electrochim. Acta 48 (2003) 1697-1705.

[111] S. Parra, V. Sarria, S. Malato, P. Péringer, C. Pulgarin, Appl. Catal. B: Environ. 27 (2000) 153-168.

[112] C. Pulgarin, M. Invernizzi, S. Parra, V. Sarria, R. Polania, P. Peringer, Catal. Today 54 (1999) 341-352.

[113] V. Sarria, P. Péringer, J. Cáceres, J. Blanco, S. Malato, C. Pulgarin, Energy 29 (2004) 853-860.

[114] M.T. García, I. Ribosa, T. Guindulain, J. Sánchez-Leal, J. Vives-Rego, Environ. Pollut. 111 (2001) 169-175.

[115] J. Bandara, C. Pulgarin, P. Péringer, J. Kiwi, J. Photochem. Photobiol. A: Chem. 111 (1997) 253-263.

[116] V. Sarria, S. Kenfack, O. Guillod, C. Pulgarin, J. Photochem. Photobiol. A: Chem. 159 (2003) 89-99.

[117] S. Parra, S. Malato, C. Pulgarin, Appl. Catal. B: Environ. 36 (2002) 131-144.

[118] S. Mohanty, N.N. Rao, P. Khare, S.N. Kaul, Water Res. 39 (2005) 5064-5070.

[119] D.F. Ollis, in: E. Pelizzetti, M. Schiavello (Eds.), Photochemical Conversion and Storage of Solar Energy, Kluwer Academic Publishers, Dordrecht, 1991

[120] W. Xi, S.-U. Geissen, Water Res. 35 (2001) 1256-1262.

[121] J. Fu, M. Ji, Z. Wang, L. Jin, D. An, J. Hazard. Mater. 131 (2006) 238-242.

[122] T.E. Doll, F.H. Frimmel, Water Res. 39 (2005) 847-854.

[123] C. Camera Roda, F. Santarelli, Proceedings of Engineering with Membranes, vol. I, Granada, Spain, June 3-6, 2001, pp. 334-339.

[124] R. Molinari, L. Palmisano, E. Drioli, M. Schiavello, J. Membr. Sci. 206 (2002) 399-415.

[125] R. Molinari, M. Borgese, E. Drioli, L. Palmisano, M. Schiavello, Catal. Today 75 (2002) 77-85.

[126] R. Molinari, F. Pirillo, M. Falco, V. Loddo, L. Palmisano, Chem. Eng. Proc. 43 (2004) 1103-1114.

[127] R. Molinari, L. Giorno, E. Drioli, L. Palmisano, M. Schiavello, in: A.I. Schäfer, A.G. Fane, T.D. Waite (Eds.), Nanofiltration Principles and Applications, Elsevier, Oxford, UK, 2005, pp. 435-458 (Chapter 18).

[128] P. Meares, Synthetic Membranes: Science, Engineering and Applications, Peidel, Dordrecht, 1986

[129] V. Augugliaro, E. García-López, V. Loddo, S. Malato, I. Maldonado, G. Marcì, R. Molinari, L. Palmisano, Solar Energy 79 (2005) 402-408.

[130] R.K. Herz, Chem. Eng. J. 99 (2004) 237-245.

[131] T. Tsuru, T. Toyosada, T. Yoshioka, M. Asaeda, J. Chem. Eng. Jpn. 36 (2003) 1063-1069.

[132] M.A. Artale, V. Augugliaro, E. Drioli, G. Golemme, C. Grande, V. Loddo, R. Molinari, L. Palmisano, M. Schiavello, Ann. Chim. 91 (2001) 127-136.

[133] T. Tsuru, Y. Ohtani, T. Yoshioka, M. Asaeda, Kagaku Kogaku Ronbunshu 31 (2005) 108-114. 
[134] A.J. Maira, W.N. Lau, C.Y. Lee, P.L. Yue, C.K. Chan, K.L. Yeung, Chem. Eng. Sci. 58 (2003) 959-962.

[135] T. Tsuru, T. Kan-no, T. Yoshioka, M. Asaeda, Catal. Today 82 (2003) $41-48$.

[136] T. Tsuru, T. Kan-no, T. Yoshioka, M. Asaeda, J. Membr. Sci. 280 (2006) 156-162.

[137] J.C. Kennedy, A.K. Datye, J. Catal. 179 (1998) 375-389.

[138] R.W. Matthews, J. Catal. 113 (1988) 549-555.

[139] J.C. Crittenden, R.P.S. Suri, D.L. Perram, D.W. Hand, Water Res. 31 (1997) 411-418.

[140] J. Matos, J. Laine, J.-M. Herrmann, Appl. Catal. B: Environ. 18 (1998) 281-291.
[141] J.-M. Herrmann, J. Matos, J. Disdier, C. Guillard, J. Laine, S. Malato, J. Blanco, Catal. Today 54 (1999) 255-265.

[142] I. Ilisz, A. Dombi, K. Mogyorósi, A. Farkas, I. Dékány, Appl. Catal. B: Environ. 39 (2002) 247-256

[143] I. Ilisz, A. Dombi, K. Mogyorósi, I. Dékány, Colloids Surf. A: Physicochem. Eng. Aspects 230 (2004) 89-97.

[144] C.H. Ao, S.C. Lee, Chem. Eng. Sci. 60 (2005) 103-109.

[145] F. Shiraishi, S. Yamaguchi, Y. Ohbuchi, Chem. Eng. Sci. 58 (2003) 929-934.

[146] P. Chin, L.P. Yang, D.F. Ollis, J. Catal. 237 (2006) 29-37. 